\title{
Exploring the Anti-quorum Sensing and Antibiofilm Efficacy of Phytol against Serratia marcescens Associated Acute Pyelonephritis Infection in Wistar Rats
}

\author{
Ramanathan Srinivasan ', Ramar Mohankumar' ${ }^{2}$ Arunachalam Kannappan ', \\ Veeramani Karthick Raja ${ }^{1}$, Govindaraju Archunan ${ }^{3}$, Shunmugiah Karutha Pandian ${ }^{1}$, \\ Kandasamy Ruckmani ${ }^{2 *}$ and Arumugam Veera Ravi ${ }^{1 *}$
}

${ }^{1}$ Department of Biotechnology, Alagappa University, Karaikudi, India, ${ }^{2}$ Department of Pharmaceutical Technology, National Facility for Drug Development for Academia, Pharmaceutical and Allied Industries, Bharathidasan Institute of Technology, Anna University, Tiruchirappalli, India, ${ }^{3}$ Department of Animal Science, Centre for Pheromone Technology, Bharathidasan University, Tiruchirappalli, India

Quorum Sensing (QS) mechanism, a bacterial density-dependent gene expression system, governs the Serratia marcescens pathogenesis through the production of virulence factors and biofilm formation. The present study demonstrates the anti-quorum sensing (anti-QS), antibiofilm potential and in vivo protective effect of phytol, a diterpene alcohol broadly utilized as food additive and in therapeutics fields. In vitro treatment of phytol (5 and $10 \mu \mathrm{g} / \mathrm{ml}$ ) showed decreasing level of biofilm formation, lipase and hemolysin production in S. marcescens compared to their respective controls. More, microscopic analyses confirmed the antibiofilm potential of phytol. The biofilm related phenomenons such as swarming motility and exopolysccharide productions were also inhibited by phytol. Furthermore, the real-time analysis elucidated the molecular mechanism of phytol which showed downregulation of fimA, fimC, flhC, flhD, bsmB, pigP, and shIA gene expressions. On the other hand, the in vivo rescue effect of phytol was assessed against $S$. marcescens associated acute pyelonephritis in Wistar rat. Compared to the infected and vehicle controls, the phytol treated groups (100 and $200 \mathrm{mg} / \mathrm{kg}$ ) showed decreased level of bacterial counts in kidney, bladder tissues and urine samples on the 5th post infection day. As well, the phytol treatment showed reduced level of virulence enzymes such as lipase and protease productions compared to the infected and vehicle controls. Further, the infected and vehicle controls showed increasing level of inflammatory markers such as malondialdehyde (MDA), nitric oxide (NO) and myeloperoxidase (MPO) productions. In contrast, the phytol treatment showed decreasing level of inflammatory markers. In histopathology, the uninfected animal showed normal kidney and bladder structure, wherein, the infected animals showed extensive infiltration of neutrophils in kidney and bladder tissues. In contrast, the phytol treatment showed normal kidney and bladder tissues. Additionally, the toxic effect of phytol $(200 \mathrm{mg} / \mathrm{kg}$ ) was assessed by single dose toxicity analysis. No changes were 
observed in hematological, biochemical profiles and histopathological analysis of vital organs in phytol treated animals compared to the untreated controls. Hence, this study suggested the potential use of phytol for its anti-QS, antibiofilm and anti-inflammatory properties against $S$. marcescens infections and their associated inflammation reactions.

Keywords: acute pyelonephritis, antibiofilm, anti-inflammatory agents, anti-quorum sensing, phytol, Serratia marcescens, Wistar rat

\section{INTRODUCTION}

Urinary tract infection (UTI) is one among the utmost commonly detected infections in clinical settings (Hvidberg et al., 2000). In divergence to men, women are more vulnerable to UTI (Derbie et al., 2017). Almost 1 in 3 women will have had UTI by the age of 24 years. Nearly half of all female population will experience with UTI throughout their lifetime. The expenses have extended for the treatment of UTI infection is $\$ 2.4$ billion a year by means of 4.5-6.8 million cases in worldwide (Foxman and Brown, 2003). The way of UTI is well-known, which starts from urethral to bladder and then moving up the ureters into the kidneys. Cystitis, a predominant UTI, takes place in the bladder of the lower urinary tract whereas the pyelonephritis, a severe kidney infection, that targets the upper urinary tract. Pyelonephritis is a potentially life threatening infection that often leads to renal damaging (Katsiari et al., 2012). Pyelonephritis occurs subsequently a sequence of events carrying the bacteria from outside of the human body, up to the bladder and finally settles down into the kidneys. If the pyelonephritis is not treated, this can lead to severe renal abscesses and sepsis along with renal failure (Ramakrishnan and Scheid, 2005). Most pyelonephritis infections are occurred by bacterial pathogens ascent through the urethra and urinary bladder. The etiologic agents of pyelonephritis are Escherichia coli, Proteus mirabilis, Pseudomonas aeruginosa, and Serratia marcescens (Ohno et al., 2003; Mittal et al., 2009; Chen et al., 2012; Kufel et al., 2016).

Serratia marcescens, a Gram-negative bacterium, belongs to the family Enterobacteriaceae, frequently isolated from urinary and respiratory tracts and it can function as an opportunistic pathogen in immunocompromised patients (Kida et al., 2007). The infections caused by $S$. marcescens are hard to treat since it possesses inherent resistance to an extensive variety of antibiotics (Lee et al., 2005; Kim et al., 2013; Leclercq et al., 2013; Liou et al., 2014; González-Juarbe et al., 2015). Development of antibiotic resistance in $S$. marcescens demands the urgent need for the alternative treatment approaches. Host-pathogen interaction and the ability of pathogens to modify the host response is a crucial factor for establishing successful infections (Youn et al., 1992). This capability of a pathogen is typically attributed to their ability to secrete several of virulence factors and to alter host immune response (McMillen et al., 1996). The prominence of these responses has been exposed in several biological processes through an assortment of inflammatory mediators and cytokines, which include tissue inflammation, wound healing and immune defense (McMillen et al., 1996; Rumbaugh et al., 2004). Recently, several reports specified that the quorum sensing
(QS) mediated virulence factors are important for successful establishment of bacterial infection in animal models (Kumar et al., 2009; Gupta et al., 2013b). QS is a vital global gene regulatory machinery in bacteria that allows discrete bacteria to coordinate their virulence behavior in a cell density depended manner, which depends on self-produced signaling molecules called autoinducers (Rumbaugh et al., 1999). Serratia marcescens has a well described QS system (SmaI/SmaR) which utilizes different homoserine lactones (HSLs) such as C4-HSL, C6-HSL, and C8-HSL as signal molecules and governs the secretion of extensive range of virulence factors such as prodigiosin, lipase, protease, chitinase, nuclease, siderophore production, hemolysin production and most importantly biofilm formation (Hines et al., 1988; Eberl et al., 1996; Horng et al., 2002; Rice et al., 2005).

Research targeting the bacterial QS system has paid a great deal of attention for the identification of effective anti-quorum sensing (anti-QS) and antibiofilm agents. These anti-QS agents aim the virulence factors production rather the growth of the bacterial pathogen, hence the emergence of selective pressure for the development of antibiotic resistance strain is nullified. Thus, it is foreseen that the inhibition of such QS mechanism would warrant as an effective approach to reduce the $S$. marcescens pathogenicity and infection (Labbate et al., 2007). Recently, numerous studies have been continuously reported the anti-QS and antibiofilm potential of several natural compounds from plant origin. Plant sources play a vital role in delivering the novel drugs candidates in medicinal field. Phytol, a diterpene alcohol compound majorly found in essential oils, extensively used as fragrant ingredient in shampoos, cosmetics, fragrances and other toiletries (Islam et al., 2015). As well, it is also used in the production of Vitamin K and E. In therapeutic field, phytol has shown antioxidant and antinociceptive activities as well as antiallergic, antimicrobial, antiradical, anti-cholinesterase, antiamyloidogenic, and anti-inflammatory properties along with adequate safety (Inoue et al., 2005; Lim et al., 2006; Ryu et al., 2011; Santos et al., 2013; Pejin et al., 2014; Lee et al., 2016; Sathya et al., 2017). Also, the phytol is a tremendous immuno stimulant, in respect of long term memory stimulation of both acquired and innate immunity. However, the report on antiQS potential of phytol against bacterial pathogens is very much scarce (Pejin et al., 2015) and the protective effect of phytol on bacterial pathogens in animal model is nil. Based on these facts, this pioneering study primarily focused on assessing the in vitro anti-QS and antibiofilm potential of phytol against $S$. marcescens and the in vivo protective effect of phytol against $S$. marcescens associated acute pyelonephritis infection in rat model. 


\section{MATERIALS AND METHODS}

\section{Uropathogenic Serratia marcescens and Its Growth Conditions}

Serratia marcescens strain PS1, a clinical strain isolated from urine sample collected from a clinical diagnosis laboratory in Meenakshi General Hospital, Chennai by Nithya et al. (2010) and identified through 16S rRNA gene sequencing with the GenBank accession number of FJ584421. Serratia marcescens was cultured in Luria- Bertani (LB) medium (pH 7.0) for overnight at $28^{\circ} \mathrm{C}$. For the experimental purposes, the $S$. marcescens strain was sub cultured in LB medium until it reached 0.4 OD at $600 \mathrm{~nm}(1 \times$ $\left.10^{8} \mathrm{CFU} / \mathrm{ml}\right)$.

\section{Compound Preparation}

For in vitro study, one milligram of phytol (97\%, mixture of isomers, catalog no. 139912, Sigma-Aldrich, St. Louis, MO, USA) was dissolved in $1 \mathrm{ml}$ of methanol as stock solution and stored at $4{ }^{\circ} \mathrm{C}$ till further use. For in vivo study, $200 \mathrm{mg}$ of phytol was dissolved in $5 \mathrm{ml}$ of corn oil as stock solution and stored at room temperature till further use. The maximum amount of methanol $(10 \mu \mathrm{l}, 1 \%)$ and corn oil $(750 \mu \mathrm{l})$ was used as the vehicle controls (negative controls) for in vitro and in vivo assays, respectively.

\section{Biofilm Cells Quantification by XTT Reduction Assay}

The effect of phytol on the metabolically active cells involved in biofilm formation of $S$. marcescens was evaluated by modified XTT reduction assay (Sivaranjani et al., 2016). The XTT sodium salt was prepared in phosphate buffer saline (PBS) at a concentration of $0.2 \mathrm{mg} / \mathrm{ml}$ and menadione in acetone at 0.172 $\mathrm{mg} / \mathrm{ml}$ concentration. For each experiment, the XTT/menadione reagent was freshly prepared in the ratio of 12.5:1. Serratia marcescens culture was inoculated in 24-well microtitre plate (MTP) containing $1 \mathrm{ml}$ of respective growth medium in the absence and presence of phytol $(5 \& 10 \mu \mathrm{g} / \mathrm{ml})$ and incubated at $28^{\circ} \mathrm{C}$ for $24 \mathrm{~h}$. Following incubation, the planktonic cells were discarded from 24-well MTP. Then, the biofilm cells on MTP wells were washed and resuspended in $200 \mu \mathrm{l}$ of $0.9 \% \mathrm{NaCl}$. $25 \mu \mathrm{l}$ of XTT-menadione solution was added in 96-well MTP containing biofilm cell suspensions and incubated at $37^{\circ} \mathrm{C}$ for $3 \mathrm{~h}$ in dark. Finally, the absorbance of biofilm cell suspensions together with XTT-menadione solution was measured at $490 \mathrm{~nm}$ by Multilabel Reader (Molecular devices, SpectraMax M3, USA).

\section{Growth Curve Analysis}

The effect of phytol on $S$. marcescens growth was assessed by growth curve analysis. One percent of $S$. marcescens culture was added in to $100 \mathrm{ml}$ of $\mathrm{LB}$ broth supplemented with (5 and $10 \mu \mathrm{g} / \mathrm{ml}$ ) and without of phytol and the flasks were incubated in constant shaking at $120 \mathrm{rpm}$ for $18 \mathrm{~h}$ in $28^{\circ} \mathrm{C}$. The cell density was read at $600 \mathrm{~nm}$ for every 1 upto $18 \mathrm{~h}$ using Multilabel Reader (Packiavathy et al., 2013).

\section{Microscopic Investigation of S. marcescens Biofilm Formation}

To evaluate the antibiofilm potential of phytol, the light and confocal laser scanning microscopic (CLSM) analyses were done by following the method of Srinivasan et al. (2017a). After the growth of $S$. marcescens biofilm with and without of phytol on 1 $\times 1 \mathrm{~cm}$ glass slides, the planktonic cells were removed by washing with distilled water. Then the glass slides were stained with $0.4 \%$ crystal violet and $0.2 \%$ acridine orange for light and confocal microscopes, respectively. After 2 min of incubation, the excess stain was removed by distilled water wash and biofilms on glass slides were imaged under light (Nikon Eclipse Ti 100, Tokyo, Japan) and CLSM (Model LSM 710, Carl Zeiss, Oberkochen, Germany) at a magnification of $400 \times$ and $200 \times$, respectively. The Z-Stack CLSM images were analyzed using COMSTAT software to obtain the average thickness, biofilm biomass and surface to volume ratio of the phytol treated and untreated $S$. marcescens biofilm (Heydorn et al., 2000).

\section{Effect of Phytol on S. marcescens Swarming Motility}

The inhibitory effect of phytol on S. marcescens swarming motility was assessed by the method of Packiavathy et al. (2013). Briefly, the $5 \mu \mathrm{l}$ of $S$. marcescens culture was inoculated in the center of swarming agar plate ( $1 \%$ peptone, $0.5 \% \mathrm{NaCl}$, and $0.5 \%$ agar) with the absence and presence of phytol (5 and $10 \mu \mathrm{g} / \mathrm{ml})$. Then, the swarming plates were incubated for $16 \mathrm{~h}$ at $28^{\circ} \mathrm{C}$ and observed for inhibition in swarming motility.

\section{EPS Quantification}

Extraction of EPS from phytol treated and untreated $S$. marcescens culture was carried out by phenol-sulfuric acid method as described by Hirs (1967) with slight modification. Briefly, the $S$. marcescens culture was grown with the absence and presence of phytol ( 5 and $10 \mu \mathrm{g} / \mathrm{ml}$ ) for $18 \mathrm{~h}$ at $28^{\circ} \mathrm{C}$ in 24 well MTP. After incubation, the planktonic cells were washedout by sterile distilled water. Then the biofilm cells were dissolved by $0.9 \% \mathrm{NaCl}(1 \mathrm{ml})$ and equilibrated phenol $(1 \mathrm{ml})$. Afterward, 5 volume of $\mathrm{H}_{2} \mathrm{SO}_{4}$ was added to mix and incubated in dark at room temperature for $1 \mathrm{~h}$. Then the absorbance was taken at $490 \mathrm{~nm}$. The percentage of EPS inhibition was calculated by using the following formula.

$$
((\text { ControlOD }- \text { TreatedOD }) / \text { ControlOD }) \times 100 \text {. }
$$

\section{Lipase Quantification Assay}

The phytol treated (5 and $10 \mu \mathrm{g} / \mathrm{ml}$ ) and untreated $S$. marcescens culture was centrifuged at 10,000 rpm for $10 \mathrm{~min}$. Then $100 \mu \mathrm{l}$ of phytol treated and untreated CFCS was added to $900 \mu \mathrm{l}$ of buffered substrate mixture having 9 volumes of $0.1 \%$ gummi arabicum and $0.2 \%$ sodium deoxycholate in $50 \mathrm{mM} \mathrm{Na} \mathrm{PO}_{4}$ buffer $(\mathrm{pH} 8.0)$ and 1 volume of $0.3 \%$-nitrophenyl palmitate in isopropanol and incubated at room temperature for $1 \mathrm{~h}$. After incubation, the reaction was dismissed by adding $1 \mathrm{ml}$ of $1 \mathrm{M}$ $\mathrm{Na}_{2} \mathrm{CO}_{3}$ following which the mixture was centrifuged at 10,000 $\mathrm{rpm}$ for $10 \mathrm{~min}$. Then, the absorbance of the supernatant was measured by Multilabel Reader at $410 \mathrm{~nm}$ (Srinivasan et al., 
2017b). The percentage of lipase inhibition was calculated by using the formula as mentioned above.

\section{Haemolysin Quantification Assay}

Fresh sheep blood was washed twice with PBS (pH 7.4) and resuspended in the same to a final concentration of $2 \%(\mathrm{v} / \mathrm{v})$. To the $500 \mu \mathrm{l}$ of $2 \%$ washed sheep erythrocytes, an equal volume of bacterial CFCS (treated with and without phytol) were added together and incubated at $37^{\circ} \mathrm{C}$ for $2 \mathrm{~h}$. Then, the tubes were centrifuged and the hemolytic activity was determined by measuring the total amount of hemoglobin released in the supernatant at OD $405 \mathrm{~nm}$ in Multilabel Reader. The percent lysis was achieved by incubating the erythrocytes with distilled water (positive control) and background lysis was determined by incubating the erythrocytes with PBS (negative control). The percentage of lysis was determined by using the following formula (Kannappan et al., 2017).

$$
\begin{aligned}
{\left[\left(\mathrm{A}_{405}\right.\right. \text { of sample }} & \left.-\mathrm{A}_{405} \text { of background }\right) /\left(\mathrm{A}_{405}\right. \text { of total } \\
& \left.\left.-\mathrm{A}_{405} \text { of background }\right)\right] \times 100 .
\end{aligned}
$$

\section{Quantitative Real-Time PCR (qPCR) Analysis}

Total RNA was extracted from phytol treated $(10 \mu \mathrm{g} / \mathrm{ml})$ and untreated $S$. marcescens by TRIzol method and isolated RNA was converted into cDNA using Invitrogen - superscript III kit. qPCR was done on an Applied Biosystems thermal cycler by Power SYBR Green PCR master mix in 7500 Sequence Detection System (Applied Biosystems Inc. Foster, CA, USA). PCR cycles comprised an initial denaturation at $95^{\circ} \mathrm{C}$ for $10 \mathrm{~min}$ followed by 40 cycles of denaturation at $95^{\circ} \mathrm{C}$ for $45 \mathrm{~s}$; annealing at $57^{\circ} \mathrm{C}$ for $45 \mathrm{~s}$; extension at $72^{\circ} \mathrm{C}$ for $50 \mathrm{~s}$. The expression patterns of candidate virulence genes were normalized against $r p l U$ gene (housekeeping gene) expression and quantified by calculating 2- $\Delta \mathrm{Ct}$. Details of the primer sequences of the candidate and housekeeping genes ( $f i m A, f i m C, f h C, f l h D, b s m B, r s s B, r s m A$, pigP, shlA, and rplU) used in this study are given in Table $\mathbf{1}$ and their efficiency was confirmed through $1.5 \%$ agarose gel electrophoresis (Supplementary Figure 1) (Salini and Pandian, 2015).

\section{In Vivo therapeutic Potential of Phytol on S. marcescens Associated Acute Pyelonephritis}

\section{Animals}

Female Wistar rat (Rattus norvegicus) weighing 100-150 g, 6-8 weeks old were used in this study. They were kept in Central Animal House, Bharathidasan University, Tiruchirappalli, India. Rats were housed in polypropylene cages and were fed with standard rat synthetic diet (Sai Durga feeds, Bangalore) and water ad libitum. Ethical clearance was approved by the Institutional Animal Ethics Committee of Bharathidasan University, Tiruchirappalli, India (Approval ID: BDU/IAEC/2016/NE/37/Dt. 17.03.2016). All the experimental protocols were followed as per the guidelines of the Committee for the purpose of Control and Supervision of Experiments on Animals (CPCSEA), Government of India.
TABLE 1 | Nucleotide sequences of $S$. marcescens primers used in this study.

\begin{tabular}{lll}
\hline \multirow{2}{*}{ Gene } & \multicolumn{2}{c}{ Primer sequence $\left(\mathbf{5}^{\prime} \mathbf{- 3}^{\mathbf{\prime}} \mathbf{)}\right.$} \\
\cline { 2 - 3 } & Forward & Reverse \\
\hline rp/U & GCTTGGAAAAGTGGACATC & TACGGTGGTGTTACGACGA \\
fimA & ACTACACCCTGCGTTCGAC & GCGTTAGATTTGCCTGACC \\
fimC & AAGATCGCACCGTACAAACC & TाGCACCGCATAGTTCAAG \\
flhC & AAGAAGCCAAGGACATTCAG & TTCCCAGGTCATAAACCAGT \\
flhD & TGTCGGGATGGGGAATATGG & CGATAGCTCTTGCAGTAATGG \\
bsmB & CCGCCTGCAAGAAAGACT & AGAGATCGACGGTCAGTTCC \\
rssB & TAACGAACTGCTGATGCTGT & GATCTTGCGCCGTAAATAT \\
rsmA & TTGGTGAAACCCTCATGATT & GCTTCGGAATCAGTAAGTCG \\
pigP & GAACATGTTGGCAATGAAAA & ATGTAACCCAGGAATGCAC \\
shlA & GCGGCGATAACTATCAAAAT & ATTGCCAGGAGTAGAACCAG \\
\hline
\end{tabular}

\section{Establishment of Experimental Acute Pyelonephritis in Rat}

An experimental model of acute pyelonephritis infection was established in female Wistar rat as described by Brown (2011). Briefly, the rats were anesthetized with a ketaminexylazine cocktail (90 mg ketamine $+9 \mathrm{mg}$ xylazine) administered intraperitoneally at a dosage of $0.1 \mathrm{ml} / 100 \mathrm{~g}$ of body weight. Then, the rat was controlled in dorsal recumbency to facilitate way of the catheter. The rat body was hold in the nondominant hand with the tail positioned between the index and middle fingers and applies trivial pressure to the tail to spread. The exterior urethral orifice was identified. Then, the thumb has placed on the ventral stomach $1 \mathrm{~cm}$ forward to the urethral opening and gentle pressure was applied to pull the skin toward the head. This help to make the urethral opening further protruding as well to stretch the urethra to enable way of the catheter (Figure 1B). A small amount of lubricant was applied at the tip of the urethral orifice and the 20-gauge IV angiocatheter (Figure 1A) has inserted into the urethral opening in the direction of the tail till it reaches the vaginal opening (Figure 1C). After reaching the vaginal opening, the catheter was gently rotated upward to the rat (Figure 1D) and then $200 \mu \mathrm{l}$ of $S$. marcescens bacterial inoculum $\left(1 \times 10^{8} \mathrm{CFU} / \mathrm{ml}\right)$ was gently injected into the bladder (Figure 1E) to avoid leak and reflux, kept in room for $10 \mathrm{~min}$ and then withdrawn prudently.

For experimental purpose animals were divided into four groups consisting of 5 animals each: (i) Group I - Infection control (Infection was given with S. marcescens cells to bladder through urethra); (ii) Group II - Vehicle control (Infection was given with $S$. marcescens cells and corn oil was given orally to infected animals after $24 \mathrm{~h}$ post infection (p.i.) until the 5 th postinfection day (p.i.d.) for daily); (iii) Group III - Animals treated with phytol (Infected animals were treated daily with an oral dose of phytol ( $100 \mathrm{mg} / \mathrm{kg}$ body weight) after $24 \mathrm{~h}$ p.i. until the 5 th p.i.d.); (iv) Group IV - Animals treated with phytol (Infected animals were treated daily with an oral dose of phytol $(200 \mathrm{mg} / \mathrm{kg}$ body weight) after $24 \mathrm{~h}$ p.i. until the 5th p.i.d). After 5th p.i.d, the urine from each rat was collected in microfuge tubes by mild compression of the abdomen. Then the animals were sacrificed and organs were collected for further assays. 


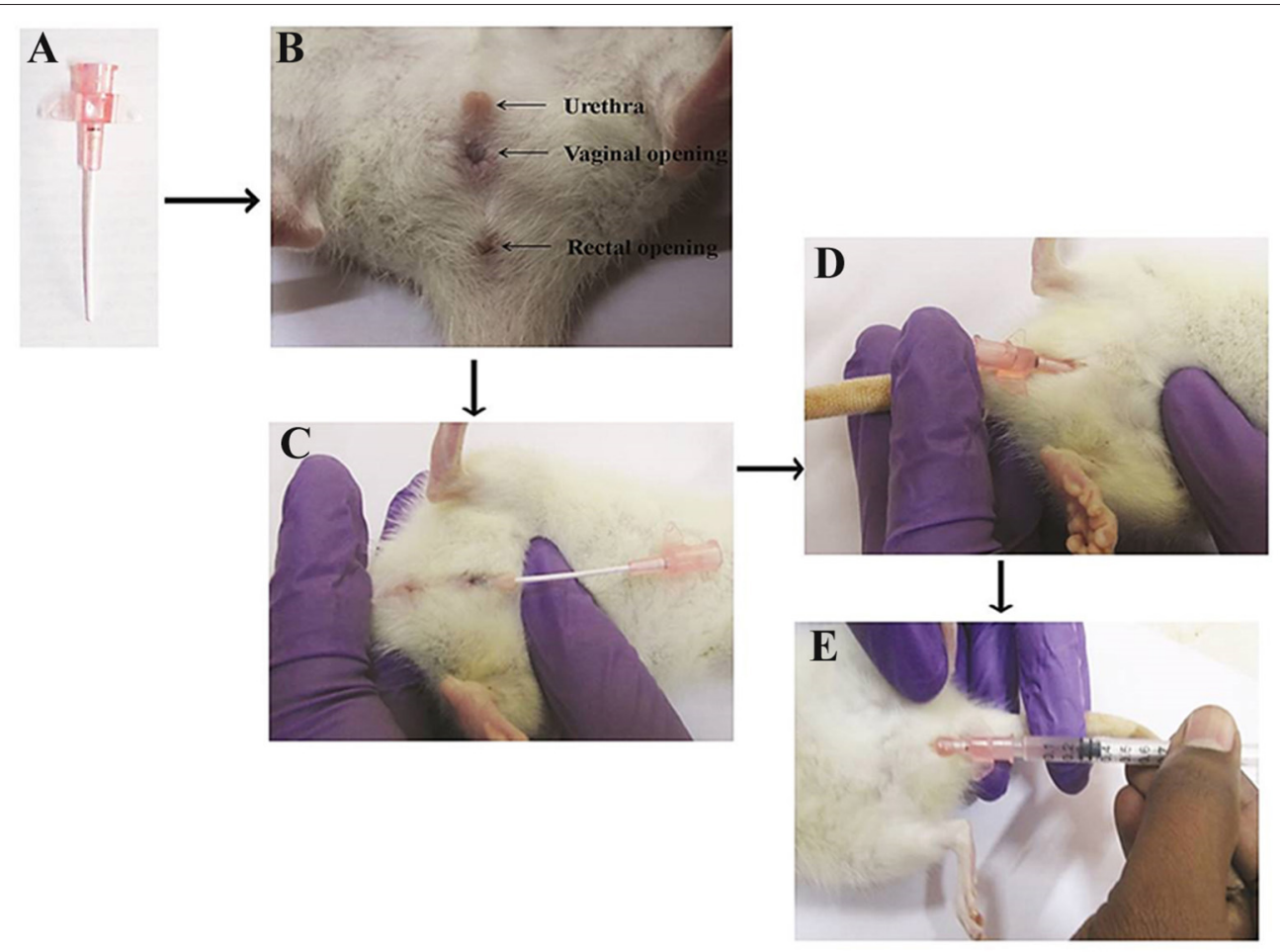

FIGURE 1 | Urinary catheterization of angiocatheter into the bladder through the urethra. Twenty-gauge IV angiocatheter (A), three visible urethral, vaginal and rectal opening (B), insertion of angiocatheter into the urethral opening till it reaches the vaginal opening (C), rotation of angiocatheter upward to the rat (D), and injection of S. marcescens bacterial inoculum into the bladder $(\mathbf{E})$.

\section{Bacteriological Examination of Urine, Kidney, and Bladder Tissues}

On the 5th p.i.d., animals from the all the groups were sacrificed. Kidney and bladder were removed aseptically, weighed and homogenized in $1 \mathrm{ml}$ of phosphate buffered saline. Bacterial count was made afterward plating the appropriate dilutions of tissue homogenates and urine samples on Serratia differential agar (SD agar) plates (Himedia, India). Log bacterial counts were calculated per gram of tissue and per $\mathrm{ml}$ of urine as reported by Kumar et al. (2009). Further, the tissue homogenates were spun at $10,000 \mathrm{rpm}$ for $10 \mathrm{~min}$ and filtered by $0.22 \mu \mathrm{m}$ cellulose acetate membrane filter (Millipore, Bangalore, India). The obtained tissue homogenate filtrate was used for the estimation of protease and lipase production.

\section{Estimation of Protease Production}

Proteolytic activity was estimated by the method of Gupta et al. (2013a) with little modification. Briefly, the reaction mixture containing $200 \mu \mathrm{l}$ of tissue homogenate diluted in $250 \mu \mathrm{l}$ of buffered substrate [ $2 \%$ of azocasein (Sigma, USA) as substrate in $1 \mathrm{M}$ Tris- $\mathrm{HCl}(\mathrm{pH}-8.0)$ ] was incubated at $37^{\circ} \mathrm{C}$ for $1 \mathrm{~h}$. After subsequent incubation, the reaction mixture was added with $600 \mu \mathrm{l}$ of $10 \%$ trichloro acetic acid to stop the reaction. The tubes were then spun at $10,000 \mathrm{rpm}$ for $10 \mathrm{~min}$ and $600 \mu \mathrm{l}$ of supernatant was added to $700 \mu \mathrm{l}$ of $1 \mathrm{M} \mathrm{NaOH}$. Absorbance was read at $440 \mathrm{~nm}$ in Multilabel reader and results were expressed in OD value.

\section{Estimation of Lipase Production}

Lipolytic activity of kidney and bladder tissue homogenized were determined using $p$-nitro phenyl palmitate $(p$-NPP) as the substrate. Two hundred microliter of tissue homogenate were added with $900 \mu \mathrm{l}$ of reaction mix containing 1 volume of $0.3 \%$ $p$-NPP in propanol, 9 volumes of $0.1 \%$ gummi arabicum and $0.2 \%$ sodium deoxycholate in $50 \mathrm{mM} \mathrm{Na}_{2} \mathrm{PO}_{4}$ buffer ( $\mathrm{pH}-8.0$ ). The reaction mix was incubated for $1 \mathrm{~h}$ at room temperature in dark and then centrifuged at $10,000 \mathrm{rpm}$ for $10 \mathrm{~min}$. The reaction was dismissed by adding $1 \mathrm{ml}$ of $1 \mathrm{M} \mathrm{Na}_{2} \mathrm{CO}_{3}$. Then, the absorbance was read at $410 \mathrm{~nm}$ and results were expressed in OD value (Srinivasan et al., 2017b).

\section{Preparation of Cell Lysate}

The kidney and bladder tissues from the experimental groups were homogenized using lysis buffer $(10 \mathrm{mM}$ Tris ( $\mathrm{pH}-8.0)$, $20 \mathrm{mM}$ EDTA and $0.25 \%$ Triton X-100). Then the supernatants were collected separately by centrifuging the tissue homogenate at 5,000 rpm for $30 \mathrm{~min}$ at $4^{\circ} \mathrm{C}$ and the protein quantification for the supernatant was done by Bradford method for all the samples. The cell lysate was kept at $-80^{\circ} \mathrm{C}$ until further analysis.

\section{Malondialdehyde Estimation}

Induction of pathology was assessed on the base of malondialdehyde by the method of Ohkawa et al. (1979). Briefly, an equal volume of $10 \%$ ice-cold TCA was added to the cell lysate (protein concentration-100 $\mu \mathrm{g}$ ) and centrifuged at 
$5,000 \mathrm{rpm}$ for $15 \mathrm{~min}$. MDA of five different concentrations (10$50 \mathrm{ng}$ ) were used as standard. To the supernatant and standard solution, same volume of $0.67 \%$ thiobarbituric acid in $50 \%$ glacial acetic acid was added and samples were incubated at $100^{\circ} \mathrm{C}$ for $20 \mathrm{~min}$. After cooling, absorbance of the supernatant and standards were measured at $532 \mathrm{~nm}$. The values were expressed as $\mu \mathrm{M}$ of TBARS/mg of protein determined by calibration curve prepared using different concentrations of MDA standards.

\section{Quantification of Myeloperoxidase (MPO) Activity}

Quantification of tissue neutrophils through the myeloperoxidase assay was done by the method of Kim et al. (2012) with slight modification. Briefly, the tissue homogenate was centrifuged at $8,000 \mathrm{rpm}$ for $20 \mathrm{~min}$ at $4^{\circ} \mathrm{C}$. The supernatant was discarded and $10 \mathrm{ml}$ of ice-cold $50 \mathrm{mM}$ potassium phosphate buffer ( $\mathrm{pH}$ 6.0) comprising $0.5 \%$ hexadecyltrimethylammonium bromide and $10 \mathrm{mM}$ EDTA was added to the pellet. It was then subjected to sonication and the solution was centrifuged at $10,000 \mathrm{rpm}$ for $20 \mathrm{~min}$. Then, $50 \mu \mathrm{l}$ of supernatant was added with $50 \mu \mathrm{l}$ of diluted $\mathrm{H}_{2} \mathrm{O}_{2}\left(4 \mu \mathrm{l}\right.$ of $30 \% \mathrm{H}_{2} \mathrm{O}_{2}$ diluted in 96 $\mu \mathrm{l}$ of $\mathrm{d} \mathrm{H}_{2} \mathrm{O}$ ) and $200 \mu \mathrm{l}$ of $\mathrm{O}$-dianisidine mixture $(16.7 \mathrm{mg}$ of $\mathrm{O}$-dianisidine, $90 \mathrm{ml}$ of $\mathrm{d} \mathrm{H}_{2} \mathrm{O}$ and $10 \mathrm{ml}$ of potassium phosphate buffer). Three subsequent readings were taken at $450 \mathrm{~nm}$ at $30 \mathrm{~s}$ intervals. One unit of MPO defined as that degrading $1 \mu \mathrm{M}$ of $\mathrm{H}_{2} \mathrm{O}_{2}$ per min at room temperature and myeloperoxidase activity was expressed as $\mathrm{U} / \mathrm{mg}$ of tissue.

\section{Estimation of Nitrite Content}

Nitrite was estimated in the kidney and bladder tissues of experimental groups by the method of Rockett et al. (1994) with slight modification. Briefly, the cell lysate (100 $\mu \mathrm{g}$ of protein) in phosphate buffer ( $\mathrm{pH}-7.4)$ was incubated with Griess reagent (Sigma Aldrich Chemicals Ltd., St Louis, MO, USA) for $30 \mathrm{~min}$ in dark at room temperature. The supernatant was collected and the optical density was measured at $540 \mathrm{~nm}$ along with the standard (5-20 $\mu \mathrm{M}$ sodium nitrite). The nitrite content was calculated with the help of sodium nitrite standard curve and the results were showed as $\mu \mathrm{M}$ of nitrite/mg of protein.

\section{Histopathological Analysis of Kidney and Bladder Tissues}

Kidney and bladder tissues were fixed in $10 \%$ buffered normal saline and dehydrated in gradient ethanol (30-100\%). Paraffin wax blocks were prepared and thin sections were stained by hematoxylin and eosin. The pathological observations of all tissues were done through microscopy analysis by a pathologist.

\section{Pilot Single-Dose Toxicity Testing of Phytol in Wistar Rat}

The rats were accommodated at a temperature of $25 \pm 2{ }^{\circ} \mathrm{C}$ in a $12 \mathrm{~h}$ light-dark cycle and acclimatized to laboratory conditions for 10 days without presenting any abnormality or pathological variations prior to experiments. Ten rats were arbitrarily divided into two groups; each containing five rats. The first group was the animal control which received the normal water, whereas the second group was orally administered with single dose of phytol (200 mg/kg body weight) for 14 days. The animals were observed for toxic signs for the first $2 \mathrm{~h}$ afterward dosing. Finally, the number of survivors was recorded after $24 \mathrm{~h}$ and animals were then maintained for additional 13 days with regular daily observations.

\section{Hematological and Biochemical Analysis}

On the day 15, all animals were anesthetized by urethane solution and blood samples were collected through retro-orbital puncture. Blood samples were collected into 2 tubes; heparinized and nonheparinized centrifuge tubes. The heparinized blood samples were used for a hematological study which includes hemoglobin concentration, white blood cell counts (WBC), red blood cell counts (RBC), and hematocrit. The serum detached from nonheparinized blood was used for a biochemical study which includes glucose, blood urea, creatinine, Alkaline phosphatase (ALP), Serum glutamic pyruvic transaminase (SGPT), Serum glutamic oxaloacetic transaminase (SGOT), triglycerides, Very low density lipoprotein (VLDL), Low density lipoprotein (LDL), High density lipoprotein (HDL), total bilirubin, direct bilirubin, indirect bilirubin, total cholesterol, total protein, albumin and globulin.

\section{Histopathological Analysis of Vital Organs}

Immediately after collecting the blood samples, the vital organs such as kidney, liver, heart, lungs, and spleen were removed for histopathological analysis. Tissues from the animal control and the group treated with the phytol $(200 \mathrm{mg} / \mathrm{kg})$ were embedded in paraffin wax for sectioning. Further, the tissue sections were subjected to hematoxylin-eosin staining. The pathological observations of all tissues were performed through microscopic analysis by a pathologist.

\section{Statistical Analysis}

All the in vitro experiments were conducted in triplicates and repeated thrice and the in vivo experiments were conducted in quintuplicates. The statistical analyses were done by SPSS statistics v17.0. Values were expressed as mean \pm standard deviation. Student- $t$ test was used to compare the control and treated samples.

\section{RESULTS}

\section{Quantification of Biofilm Cells by XTT Reduction Assay}

The metabolically active cells involved in S. marcescens biofilm formation were quantified by XTT reduction assay. Results revealed that 5 and $10 \mu \mathrm{g} / \mathrm{ml}$ of phytol treatment showed lower level of optical density (OD 0.45 and 0.37 , respectively) when compared to the untreated and vehicle controls (OD 1.32 and 1.24, respectively) (Figure $\mathbf{2 A}$ ), which clearly indicates that phytol treatment reduces the number of metabolically active cells involved in biofilm formation.

\section{Effect of Phytol on S. marcescens Growth}

To check the non-antibacterial activity of phytol, the bacterial growth curve assay was performed with $S$. marcescens in the 

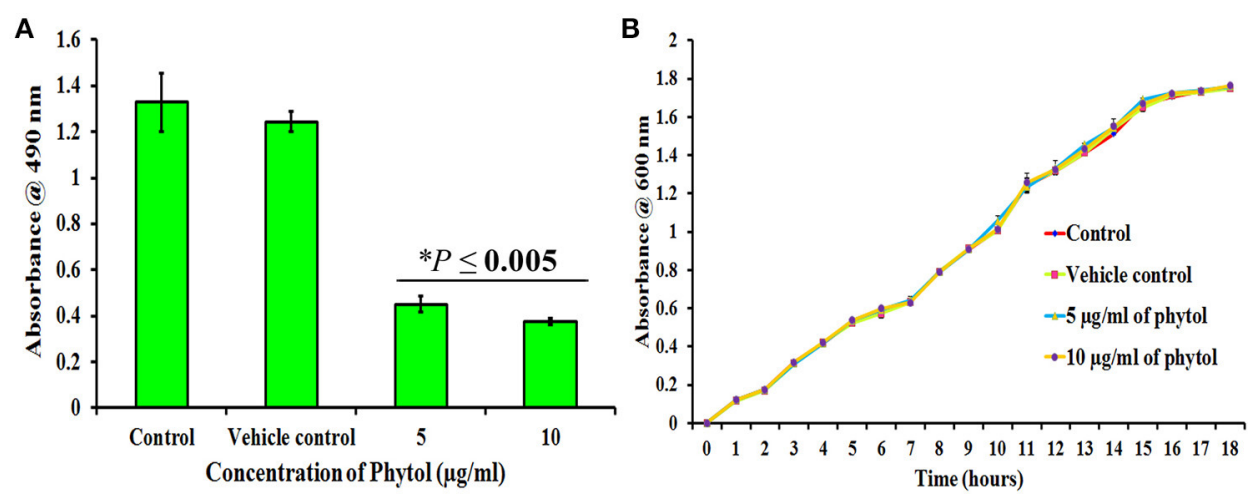

FIGURE 2 | Effect of phytol on S. marcescens biofilm formation and growth. Phytol treatment (5 and $10 \mu \mathrm{g} / \mathrm{ml})$ significantly inhibited the biofilm formation (A), without affecting the growth of $S$. marcescens (B). One percent of methanol was used as vehicle control. Error bar indicates standard deviations from the mean. Student- $t$ test was used to compare the control and treated samples. *Indicates significant at $p \leq 0.005$.

absence and presence of phytol $(5$ and $10 \mu \mathrm{g} / \mathrm{ml})$. Even after $18 \mathrm{~h}$ of incubation, no substantial differences were observed in the cell densities between untreated, vehicle controls and phytol treated samples (Figure 2B), which confirms that phytol did not have any antibacterial activity against $S$. marcescens at tested concentration.

\section{Light Microscopic and CLSM Analysis of S. marcescens Biofilm Formation}

Light microscopic observation of biofilm formation after treatment with phytol revealed their antibiofilm potential against S. marcescens. A thick coating of biofilm formation was observed in untreated and vehicle control samples, whereas a noticeable reduction of biofilm was observed in phytol treated samples (Figure 3A). In addition to this, the 2, 2.5, and 3 D CLSM images indicated the reduced in thickness and architecture of biofilms upon phytol treatment (Figure 3B). COMSTAT analysis was done to determine the $3 \mathrm{D}$ features like average thickness, biomass and surface volume ratio of $S$. marcescens biofilms with the absence and presence of phytol. The average thickness of the biofilm was reduced from $19.3 \pm 0.29$ to $12.1 \pm 0.51 \mu \mathrm{m}$ after treatment with phytol $(10 \mu \mathrm{g} / \mathrm{ml})$. Similarly, 5 and $10 \mu \mathrm{g} / \mathrm{ml}$ of phytol treatment showed reduced level of biofilm biomass (14.8 \pm 0.38 and $12.0 \pm 0.63 \mu \mathrm{m}^{3} / \mu \mathrm{m}^{2}$, respectively) compare to the untreated and vehicle controls $(20.0 \pm 0.19$ and $19.6 \pm$ $0.4 \mu^{3} / \mu \mathrm{m}^{2}$, respectively). Furthermore, 5 and $10 \mu \mathrm{g} / \mathrm{ml}$ of phytol treatment displayed increasing level of surface volume ratio $(0.13 \pm 0.08$ and $0.20 \pm 0.01$, respectively) due to their biofilm disintegration property, wherein the surface volume ratio of untreated and vehicle control samples were $0.06 \pm 0.01$ and $0.07 \pm 0$, respectively (Table 2 ).

\section{Effect of Phytol on S. marcescens Swarming Motility}

Swarming motility is a QS mediated virulence attribute in $S$. marcescens. Obtained results clearly evident that the phytol (5 and $10 \mu \mathrm{g} / \mathrm{ml}$ ) was able to reduce the $S$. marcescens swarming efficiency in a concentration dependent manner when compared to the untreated and vehicle controls (Figure 3C).

\section{Effect of Phytol on EPS Production}

Microbial cells cocooned themselves in self-secreted extra polymeric substances, which play a vital role in formation of biofilms. Phytol significantly $(P \leq 0.0005)$ inhibited the EPS production to the level of 32 and $39 \%$ at 5 and $10 \mu \mathrm{g} / \mathrm{ml}$ concentrations, respectively. Where, the vehicle control did not show any significant level of EPS inhibition (Figure 4A).

\section{Effect of Phytol on Lipase and Hemolysin Productions}

S. marcescens is known to harbor important virulence factors including hemolysin production, which helps the bacteria in lysing human red blood cells and production of QS controlled extracellular virulence enzyme lipase. Therefore, the efficacy of phytol to inhibit the lipase and hemolytic virulence property of $S$. marcescens was assessed by lipolytic and hemolytic activities. The obtained results showed that phytol significantly $(P \leq$ $0.0005)$ inhibited the lipase and hemolysin productions to the level of 42 and $31 \%$ respectively, at $10 \mu \mathrm{g} / \mathrm{ml}$ concentration (Figures 4A,B).

\section{Expression of QS Regulated Genes in S. marcescens upon Treatment with Phytol} The expression level of QS-regulated genes was assessed in the $S$. marcescens in the presence of phytol $(10 \mu \mathrm{g} / \mathrm{ml})$ using real-time quantitative PCR. Phytol at tested concentration, downregulated the expression of fimA, fim $C, f l h C, f l h D, b s m B$, pigP, and shlA genes by $0.42,0.32,0.25,0.46,0.36,0.48$, and 0.15 fold, respectively in $S$. marcescens relative to the untreated controls. In divergence, phytol upregulated the $r s s B$ and $r s m A$ gene expressions to the level of 0.96 and 0.84 fold respectively compared to the controls (Figure 5). 


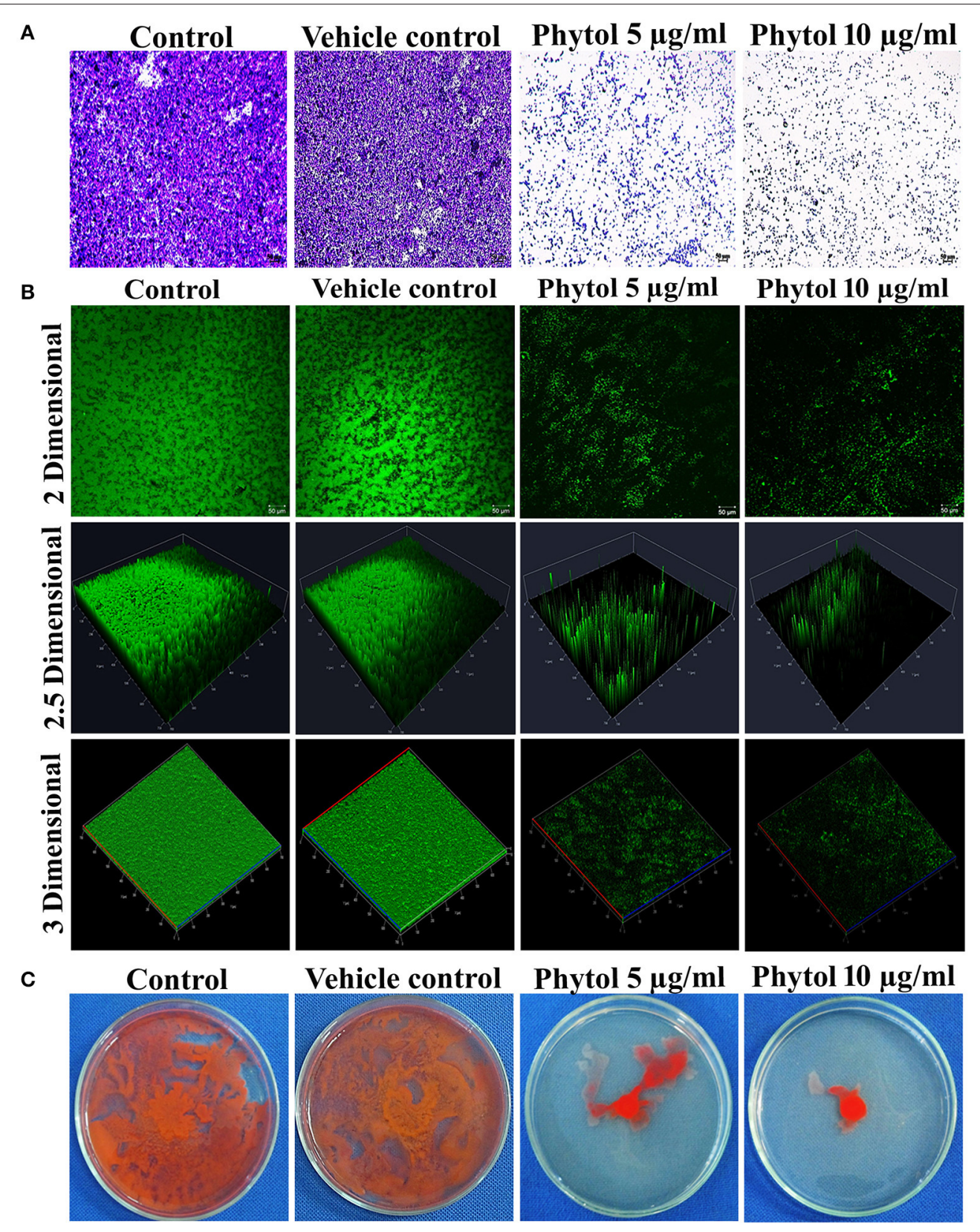

FIGURE 3 | Microscopic analyses of S. marcescens biofilm formation. Light microscopic (A) and CLSM (B) images of phytol treatment slides (5 and $10 \mu \mathrm{g} / \mathrm{ml})$ showed disintegration of $S$. marcescens biofilm formation compared to their untreated controls. Effect of phytol on $S$. marcescens swarming motility: The control plate exhibited extensive swarming motility on soft agar. In contrast, the phytol treatment ( 5 and $10 \mu \mathrm{g} / \mathrm{ml})$ considerably inhibited the $\mathbf{S}$. marcescens swarming motility (C). One percent of methanol was used as a vehicle control.

\section{In Vivo Protective Effect of Phytol on S. marcescens Associated Acute Pyelonephritis}

Morphological Changes in Kidney and Bladder of Infected and Phytol Treated Animals

Healthy kidney with smooth and normal bean shaped contours were observed in the normal uninfected rat, whereas, rat infected with $S$. marcescens by transurethral inoculation showed damaged kidney with severe abscess and pus formation. In contrast, the infected rat treated with phytol showed undamaged kidney which is similar like uninfected rat kidney (Figure 6A).

Assesment of Bacterial Burden in Urine, Kidney, and Bladder Tissues

The tissue homogenates of kidney, bladder and the urine samples were plated on SD agar plates for estimation of bacterial load. 
TABLE 2 | COMSTAT analysis of phytol treated and untreated S. marcescens biofilm.

\begin{tabular}{|c|c|c|c|c|}
\hline Parameter & Control & Vehicle control & Phytol 5 н g/ml & Phytol $10 \mu \mathrm{g} / \mathrm{ml}$ \\
\hline Biomass $\left(\mu \mathrm{m}^{3} / \mu \mathrm{m}^{2}\right)$ & $20.08641 \pm 0.19$ & $19.68098 \pm 0.4$ & $14.85047 \pm 0.38^{\star}$ & $12.06844 \pm 0.63^{\star}$ \\
\hline Average thickness ( $\mu \mathrm{m})$ & $19.3204 \pm 0.29$ & $19.12131 \pm 0.59$ & $14.78937 \pm 0.14^{*}$ & $12.1517 \pm 0.51^{\star \star \star}$ \\
\hline Surface volume ratio $\left(\mu \mathrm{m}^{2} / \mu \mathrm{m}^{3}\right)$ & $0.06664 \pm 0.01$ & $0.07418 \pm 0.00$ & $0.131617 \pm 0.08$ & $0.203123 \pm 0.01$ \\
\hline
\end{tabular}

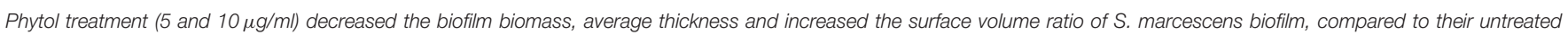

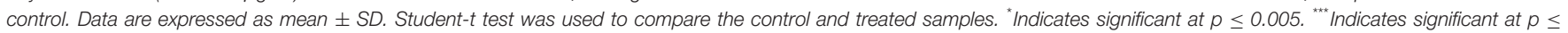
0.0005 .
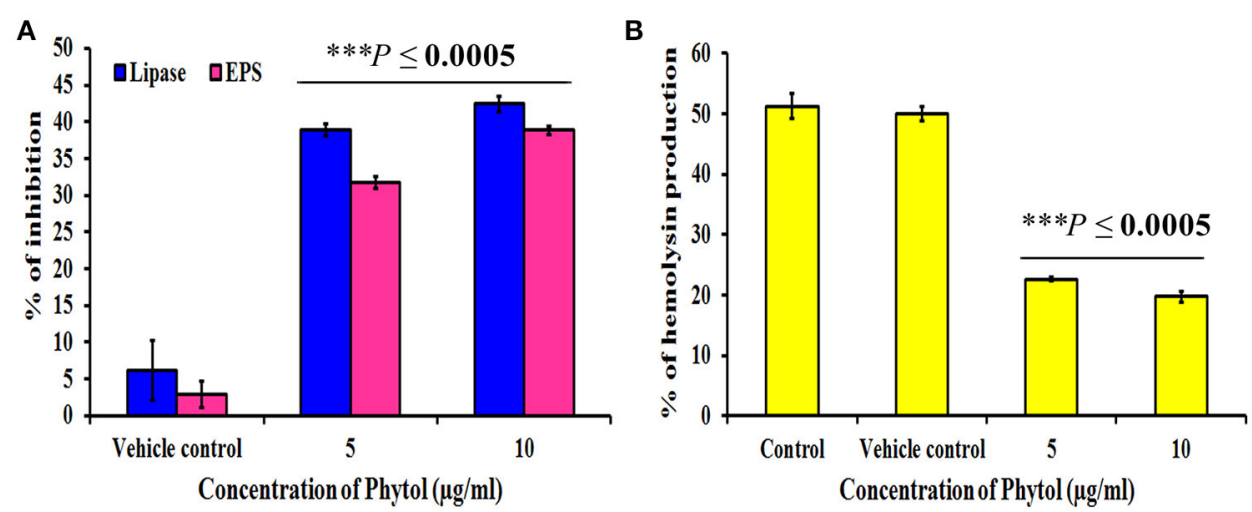

FIGURE 4 | Effect of phytol on QS mediated virulence factors production in S. marcescens. Phytol treatment (5 and $10 \mu \mathrm{g} / \mathrm{ml})$ significantly inhibited the lipase, EPS (A) and hemolysin (B) productions in S. marcescens. One percent of methanol was used as a vehicle control. Error bar indicates standard deviations from the mean. Student- $t$ test was used to compare the control and treated samples. ${ }^{\star \star \star}$ Indicates significant at $p \leq 0.0005$.

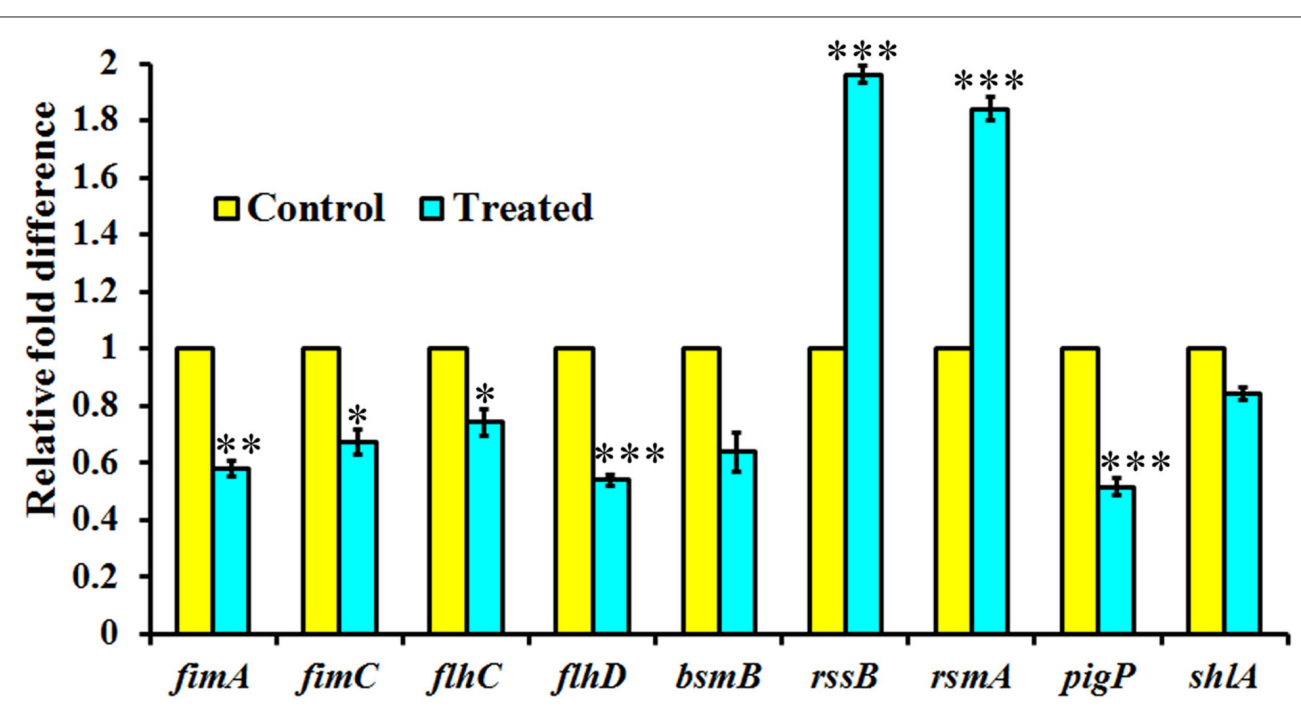

FIGURE 5 | Effect of phytol treatment on the virulence gene expression of S. marcescens. Phytol treatment (10 $\mu \mathrm{g} / \mathrm{ml}) \mathrm{modulated}$ the expression of QS controlled genes involved in virulence factors production and biofilm formation in $S$. marcescens. Error bar indicates standard deviations from the mean. Student- $t$ test was used to compare the control and treated samples. ${ }^{*}$ Indicates significant at $p \leq 0.005$, ${ }^{* *}$ indicates significant at $p \leq 0.001$, and ${ }^{* \star *}$ indicates significant at $p \leq 0.0005$.

The 100 and $200 \mathrm{mg} / \mathrm{kg}$ body weight of phytol treatment showed a significant $(P \leq 0.0005)$ decline in kidney bacterial load by $\log 6$ and 6.5 , respectively on the 5 th p.i.d compared to infected control group. On the other hand, a same level of bacterial load was observed in vehicle control group compared to the infected control (Figure 6B). A similar decreasing drift was observed with bladder and urine bacterial counts in phytol treated groups on the 5th p.i.d. The 100 and $200 \mathrm{mg} / \mathrm{kg}$ body weight of phytol treatment decreased the bladder bacterial count by $\log 5.3$ and 6.2, respectively compared with the infected control group (Figure 6C). In urine sample, the 100 and $200 \mathrm{mg} / \mathrm{kg}$ body weight of phytol treatment decreased the bacterial count by $\log 2.7$ 
A
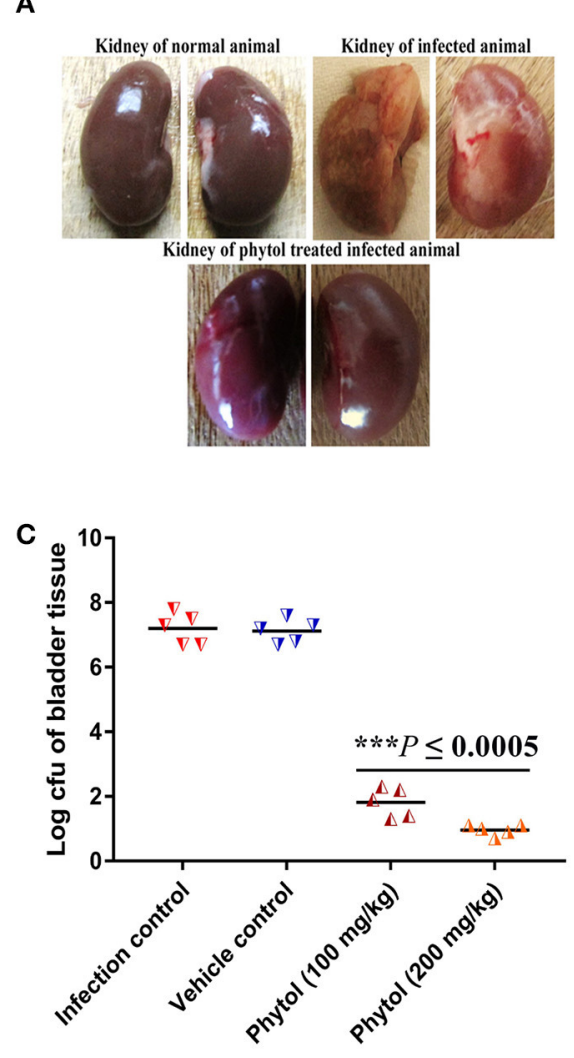

B

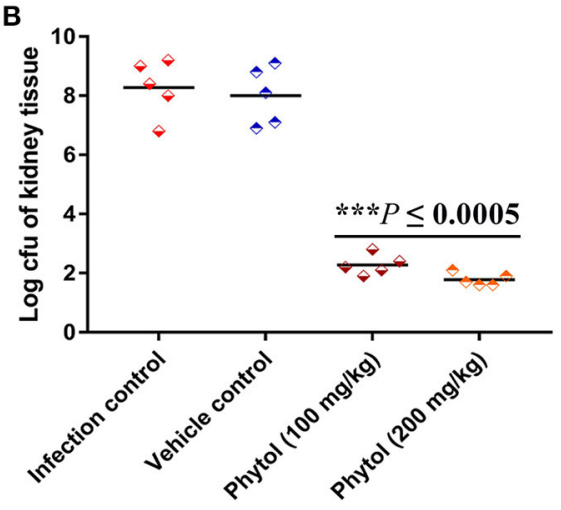

D

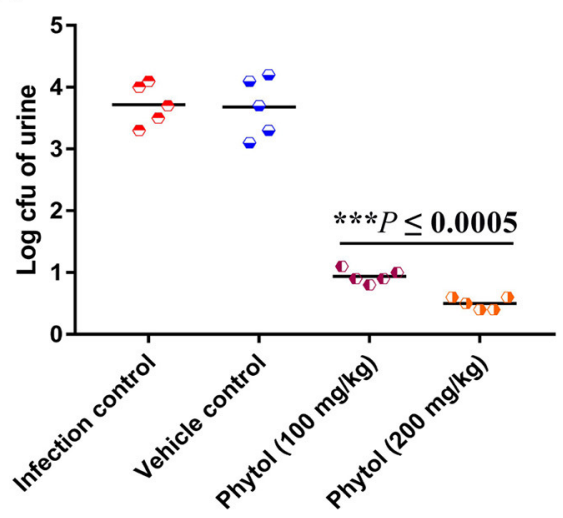

FIGURE 6 | Morphological changes in rat kidney upon treatment with and without of phytol against S. marcescens associated acute pyelonephritis infection. The image of untreated infected animal showed damaged kidney along with pus formation and severe abscess. In contrast, the image of phytol treated infected animal showed healthy kidney like normal animal (A). Quantitative bacterial load in kidney, bladder tissues, and urine samples: Compare to the infection controls, 100 and $200 \mathrm{mg} / \mathrm{kg}$ body weight of phytol treatment showed decreased level of bacterial load in kidney (B), bladder (C) tissues, and urine (D) samples. Corn oil was used as the vehicle control. Data are expressed as mean \pm SD. Student- $t$ test was used to compare the control and treated samples. ${ }^{\star \star \star}$ Indicates significant at $p \leq 0.0005$.

and 3.2, respectively compared with the infected control group (Figure 6D).

\section{Level of Protease Production in Kidney and Bladder Tissues of Phytol Treated and Untreated Infected Animals}

The protease is an extracellular virulence enzyme and its production is regulated by QS mechanism in S. marcescens. Therefore, the level of protease production in phytol treated and untreated kidney and bladder tissues were assessed. The results showed a decreased level of protease production in phytol treatment groups than the infected and vehicle controls (Figures 7A,B).

\section{Level of Lipase Production in Kidney and Bladder Tissues of Phytol Treated and Untreated Infected Animals}

Alike to protease, the production of an extracellular virulence lipase enzyme is controlled by QS mechanism. Therefore, the effect of phytol in lipase production of $S$. marcescens was assessed by lipolytic assay. The results revealed a decreased level of lipase production in phytol treatment groups compared to the infected and vehicle controls (Figures 7C,D).

\section{Effect of Phytol on MDA Production}

Free radicals mediated lipid peroxidation produces a large number of reactive aldehydes. MDA is one among the reactive aldehydes involved in pathophysiological modifications occurred during oxidative stress in tissues. Hence, the level of MDA production was estimated to assess the level of cellular injury in kidney and bladder tissues. Kidney and bladder tissues of rat infected with $S$. marcescens showed increasing level of MDA production. In contrast, phytol treatment significantly $(P \leq$ $0.0005)$ decreased the MDA production and protected the tissues from lipid peroxidation mediated damages (Figure 8A).

\section{Effect of Phytol on MPO Level}

Infiltration of neutrophils in the kidney and bladder tissues of infected rat treated with and without phytol was assessed by estimating the MPO production. MPO is an enzyme produced by neutrophils, which involves in neutralizing the deleterious effect of $\mathrm{H}_{2} \mathrm{O}_{2}$ that cause tissue injury. Assessment levels of MPO in kidney and bladder tissues of infected rats displayed augmented 

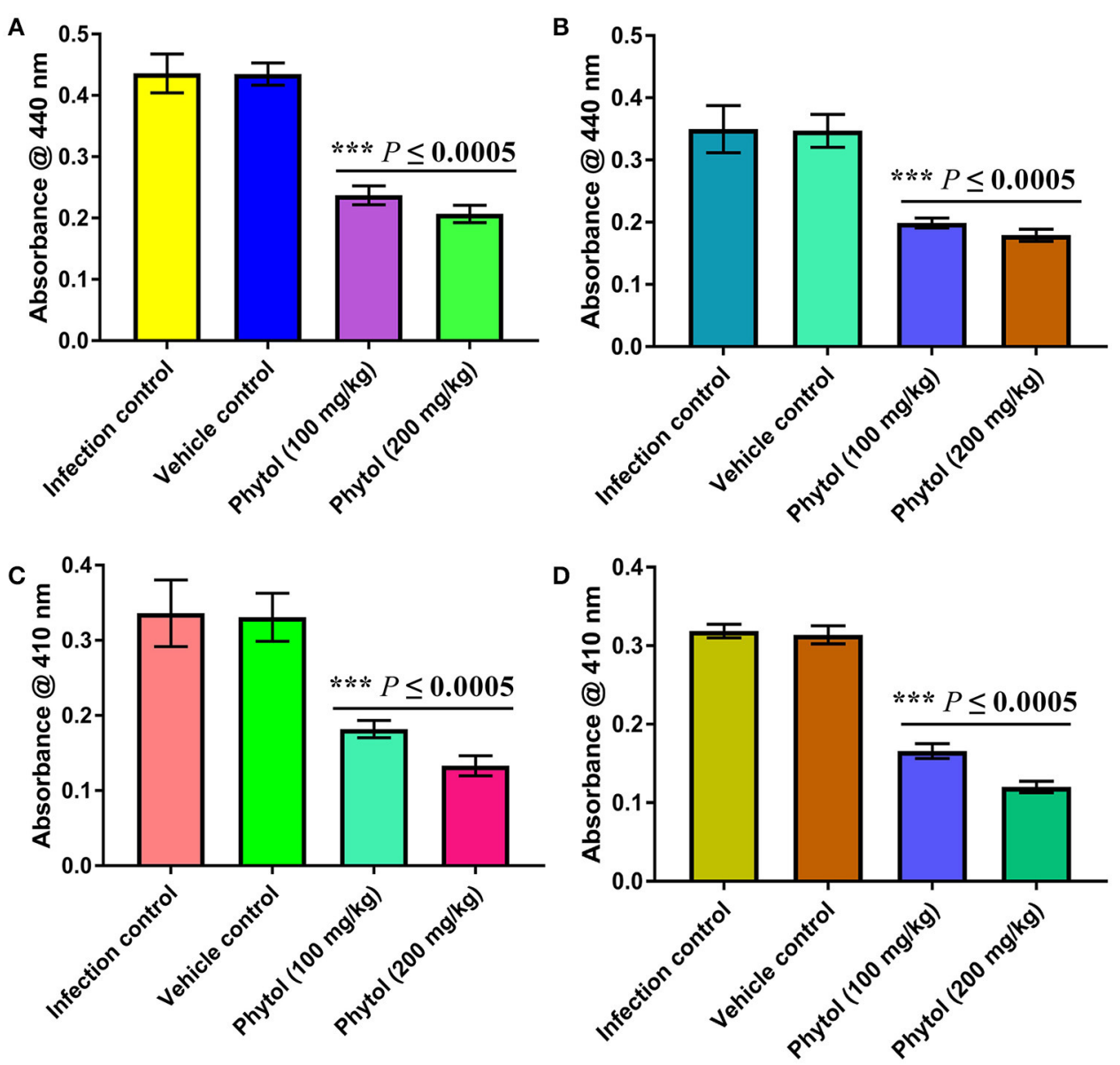

FIGURE 7 | Inhibitory effect of phytol on protease and lipase productions in kidney and bladder tissues. Phytol treatment (100 and 200 mg/kg) significantly decreased the protease $\mathbf{( A , B )}$ and lipase $\mathbf{( C , D )}$ productions in kidney $\mathbf{( A , C )}$ and bladder $\mathbf{( B , D )}$ tissues of pyelonephritis induced rats, compared to their infection controls. Corn oil was used as the vehicle control. Error bar indicates standard deviations from the mean. Student- $t$ test was used to compare the control and treated samples.

${ }^{* * *}$ Indicates significant at $p \leq 0.0005$.
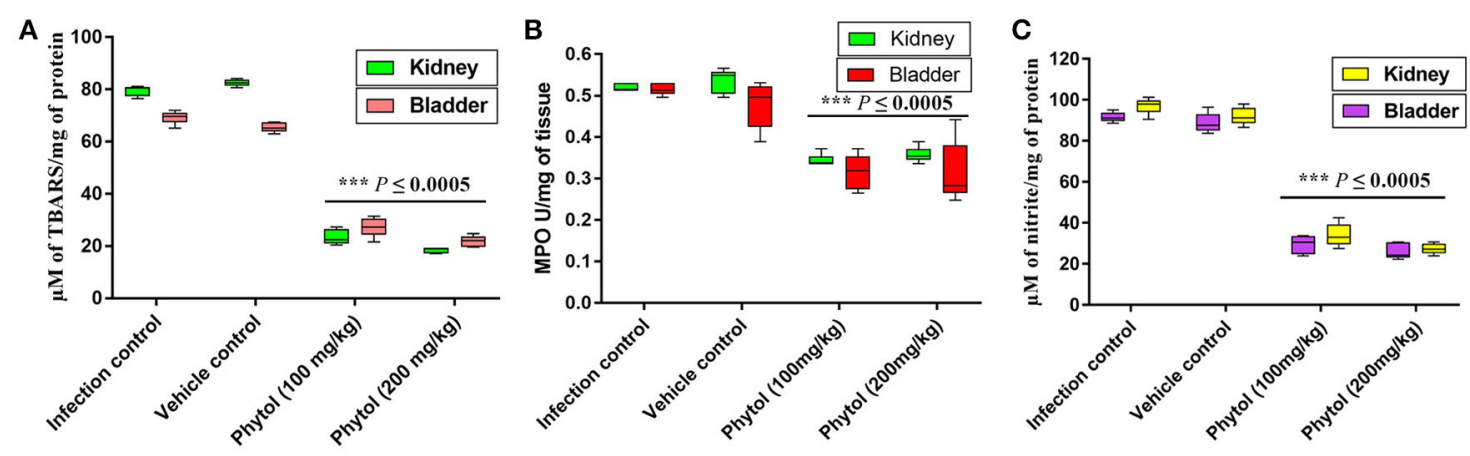

FIGURE 8 | Levels of MDA, MPO, and NO productions in kidney and bladder tissues. Phytol treatment (100 and $200 \mathrm{mg} / \mathrm{kg}$ ) significantly decreased the MDA (A), MPO (B), and NO (C) levels in kidney and bladder tissues of pyelonephritis induced rats, compared to their infection controls. Corn oil was used as the vehicle control. Error bar indicates standard deviations from the mean. Student- $t$ test was used to compare the control and treated samples. ${ }^{\star \star \star}$ Indicates significant at $p \leq 0.0005$.

level of MPO production, while, the phytol treatment exhibited a diminution level of MPO production in both kidney and bladder tissues (Figure 8B).

\section{Effect of Phytol on Nitrite Content}

Reactive nitrogen intermediates are an index of nitrite produced by macrophages and neutrophils with the help of nitric oxide 
(NO) synthase. Increased level of nitrite production was observed in the $S$. marcescens infected kidney and bladder tissues, whereas, the phytol treatment showed a decreased level of nitrite production in kidney and bladder tissues (Figure 8C).

\section{Kidney Tissue Histology}

Normal uninfected rat showed normal glomeruli (Figure 9Aa), whereas the rat infected with $S$. marcescens showed severe inflammation and dilation of Bowman's capsule, obliteration of renal tubules and widespread infiltration of neutrophils in the kidney tissue (Figure 9Ab). In vehicle control, infiltration of lymphocytes were observed near glomeruli and is representing an extensive inflammation. Destruction of renal tubules, dilatation of Bowman's capsule and glomeruli shrinkage were also observed (Figure 9Ac). In contrast, the infected rat treated with $100 \mathrm{mg} / \mathrm{kg}$ body weight of phytol showed mild infiltration of neutrophils. While, dilated Bowman's space and shrinkage of glomeruli were not observed (Figure 9Ad). Similarly, infected rat treated with $200 \mathrm{mg} / \mathrm{kg}$ body weight of phytol showed reduced level of infiltration of neutrophil and is similar to the normal animal control (Figure 9Ae).

\section{Bladder Tissue Histology}

Histological section of normal animal bladder showed normal structure of urinary bladder. The three layers of TEp, mucosa and muscularis appear to be normal (Figure 9Ba). In infection control, the increased infiltration of neutrophils was observed in the bladder wall. Also, severe mucosal abrasion was observed due to infiltration of neutrophils (Figure 9Bb). Similarly in vehicle control, marked inflammation and infiltration of neutrophil was observed in the transitional epithelium layer and larger areolar connective tissue was observed (Figure 9Bc). In contrast, the $100 \mathrm{mg} / \mathrm{kg}$ body weight of phytol treatment group showed no remarkable inflammation in the transitional epithelium layer, while, slight abrasion was observed in the urothelium
(Figure 9Bd). Histological section of urinary bladder in 200 $\mathrm{mg} / \mathrm{kg}$ body weight of phytol treatment showed clear pathological changes (Figure 9Be).

\section{Single Dose Toxicity Study Hematological and Biochemical Parameters}

The haematopoietic system is one of the utmost sensitive targets for toxic compounds and considered as a vital index of pathological and physiological status in living systems. Similarly, assessment of biochemical profile acts as valuable indicator to assess the toxic nature of drugs in man and animals. In the pilot single dose toxicity study, no noteworthy difference was observed in the hematological and biochemical profile between the animal control and the phytol treated group $(200 \mathrm{mg} / \mathrm{kg}$ ) (Table 3). Compared to animal control, a slight increament was observed in ALP and SGPT levels in the phytol treated group (200 $\mathrm{mg} / \mathrm{kg}$ ). There was a significant decrease in triglycerides and total cholesterol level in the group treated with $200 \mathrm{mg} / \mathrm{kg}$ of phytol, when compared to the animal control.

\section{Histological Evaluation of Vital Organs of Normal and Phytol Treated Animals}

Histological micrographs of kidney from untreated animal showed normal glomeruli size and the proximal and distal convoluted tubules exhibit a normal fine structures (Figure 10Aa), while $200 \mathrm{mg} / \mathrm{kg}$ phytol treatment showed intact glomeruli with normal structure (Figure 10Ba). The liver sectioning of control animals portrayed normal architecture and hepatic cells with granulated cytoplasm. The hepatocytes were polygonal shape with a rounded nucleus, arranged in cords with the portal tract exhibiting a normal structure (Figure 10Ab). The rats administered with $200 \mathrm{mg} / \mathrm{kg}$ body weight of phytol showed only a moderate degeneration of hepatocytes (Figure 10Bb). Similarly, sections of heart from control and phytol treated animals showed normal muscle fibers with acidophilic cytoplasm

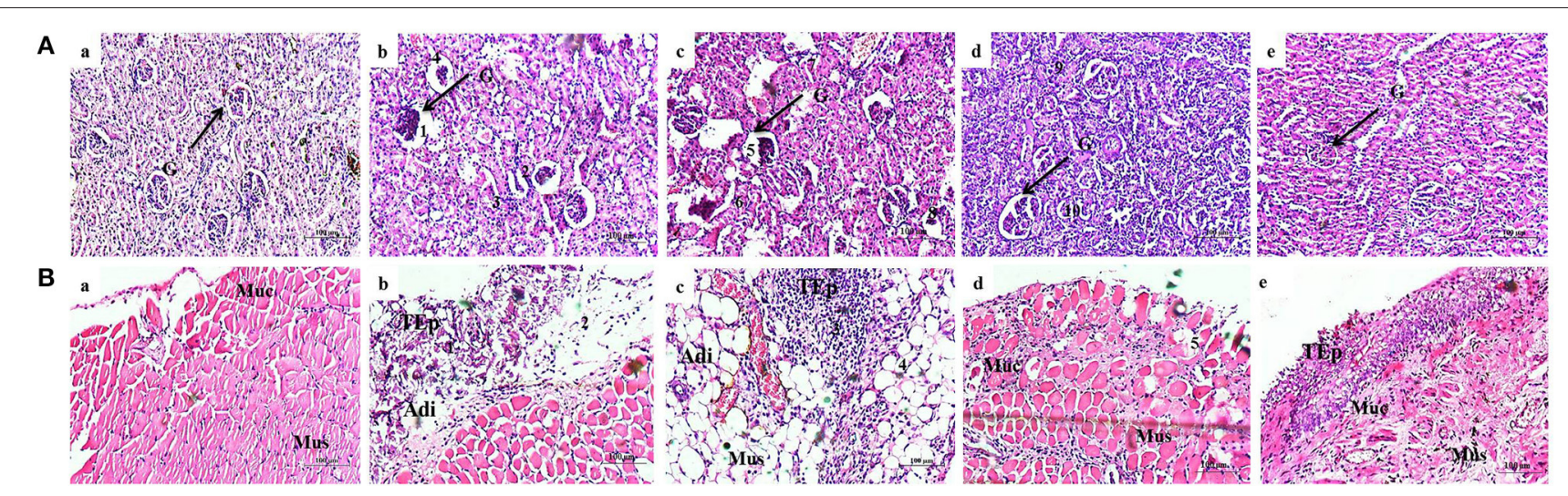

FIGURE 9 | Histopathology analysis of kidney tissue (A). Normal uninfected rat (a), infection control (b), vehicle control (c), phytol treatment (100 mg/kg) (d), phytol treatment $(200 \mathrm{mg} / \mathrm{kg})$ (e). 1 and 5, Dilation of Bowman's capsule; 2 and 6, Destruction of renal tubules; 3 and 7, Extensive infiltration of neutrophils; 4 and 8 , Shrinkage of glomeruli; 9, Mild infiltration of neutrophils; 10, Well rejuvenated renal tubules; G, Glomeruli. Histopathology analysis of bladder tissue (B). Normal uninfected rat (a), Infection control (b), Vehicle control (c), Phytol treatment (100 mg/kg) (d), Phytol treatment (200 mg/kg) (e). 1 and 3 , Extensive infiltration of neutrophils in the bladder wall; 2, Severe abrasion due to infiltration of neutrophils; 4, Larger areolar connective tissue interlaced with the muscular coat; 5, Slight abrasion; Muc, mucosa; Mus, muscularis; TEp, transitional epithelium; Adi, Adipose tissue. Corn oil was used as the vehicle control. 
and centrally located nuclei (Figures $\mathbf{1 0 A}, \mathbf{B c}$ ). The lung sections appears to be normal in phytol treated and control animals with typical alveoli (Figures 10A,Bd). The spleen from control and phytol treated animals showed normal granular hemosiderin pigment predominantly within macrophages in the red pulp. The white pulp containing lymphocytes surrounded by a red pulp (Figures 10A,Be).

TABLE 3 | Hematological and biochemical profiles of animal control and animal treated with phytol.

\begin{tabular}{|c|c|c|}
\hline $\begin{array}{l}\text { Hematological and biochemical } \\
\text { parameters }\end{array}$ & Control & Phytol 200 mg/kg \\
\hline Hemoglobin (gm/dL) & $12.16 \pm 1.8$ & $11.84 \pm 3.4$ \\
\hline $\operatorname{WBC}\left(\times 10^{3}\right)\left(\mu \mathrm{L}^{-1}\right)$ & $7.52 \pm 0.6$ & $7.18 \pm 1.5$ \\
\hline $\operatorname{RBC}\left(\times 10^{6}\right)\left(\mu L^{-1}\right)$ & $3.94 \pm 0.6$ & $3.92 \pm 1.1$ \\
\hline Hematocrit (\%) & $35.48 \pm 7.03$ & $35.58 \pm 10.2$ \\
\hline Glucose (mg/dL) & $80.6 \pm 16.1$ & $76.8 \pm 15.1$ \\
\hline Blood urea (mg/dL) & $48.24 \pm 4.6$ & $53.2 \pm 4.6$ \\
\hline Creatinine (mg/dL) & $0.542 \pm 0.3$ & $0.48 \pm 0.07$ \\
\hline ALP (IU/L) & $107.8 \pm 9.8$ & $127.6 \pm 23.9$ \\
\hline SGOT (U/L) & $39.4 \pm 7.2$ & $44.4 \pm 10.5$ \\
\hline SGPT (U/L) & $20.2 \pm 5.1$ & $27 \pm 10.4$ \\
\hline Triglycerides (mg/dL) & $96.4 \pm 6.4$ & $91 \pm 17.4$ \\
\hline $\mathrm{HDL}(\mathrm{mg} / \mathrm{dL})$ & $16.8 \pm 4.1$ & $16.6 \pm 1.4$ \\
\hline LDL (mg/dL) & $113.84 \pm 20.3$ & $105.2 \pm 10.6$ \\
\hline VLDL (mg/dL) & $18.96 \pm 1.6$ & $18.2 \pm 3.4$ \\
\hline Total bilirubin (mg/dL) & $0.384 \pm 0.1$ & $0.48 \pm 0.1$ \\
\hline Direct bilirubin (mg/dL) & $0.246 \pm 0.08$ & $0.3 \pm 0.06$ \\
\hline Indirect bilirubin (mg/dL) & $0.124 \pm 0.04$ & $0.18 \pm 0.07$ \\
\hline Total cholesterol (mg/dL) & $152.4 \pm 21.0$ & $140 \pm 8.9$ \\
\hline Total Protein (gm/dL) & $5.22 \pm 0.4$ & $5.14 \pm 0.9$ \\
\hline Albumin (gm/dL) & $3.58 \pm 0.4$ & $3.56 \pm 0.3$ \\
\hline Globulin (gm/dL) & $1.64 \pm 0.3$ & $1.58 \pm 0.5$ \\
\hline
\end{tabular}

Phytol treatment $(200 \mathrm{mg} / \mathrm{kg})$ did not show any significance variations in hematological and biochemical profiles, compared to the animal control. Data are expressed as mean $\pm S D$.

\section{DISCUSSION}

UTI is an infection occurred wherever in the urinary system typically exposed to bacterial pathogens. Once bacterial pathogens reach the kidney through ascending infection, they are capable to adhere to the urothelium before raiding the renal tissue with subsequent pyelonephritis (Nickel et al. (1987). Such sort of infections are reported to be caused by Gram-negative bacteria like P. mirabilis, E. coli, Klebsiella pneumoniae, P. aeruginosa, S. marcescens, and Gram-positive bacteria such as Staphylococcus aureus and Enterococcus faecalis (Su et al., 2003; Behzadi et al., 2010; Kaur et al., 2014).

Among which, S. marcescens is an important human opportunistic bacterial pathogen, causing numerous nosocomial infections such as respiratory tract infections, blood stream infections, ocular infections and most importantly urinary tract infections (Hejazi and Falkiner, 1997). It secretes array of virulence factors and forms biofilm via signal mediated QS mechanism. In our previous study, we assessed the anti-QS potential of phytol through primary assays such as prodigiosin production, protease inhibition assays and biofilm cells quantification by crystal violet assay (Srinivasan et al., 2016). Nevertheless, the present study further evaluated the potentials of phytol against $S$. marcescens by assessing various virulence assays such as biofilm cells quantification by XTT reduction assay, microscopic analyses of biofilm formation, swarming motility analysis, lipase, hemolysin and EPS quantification assays. In addition, the current study elucidated the molecular mechanism of phytol on QS system in S. marcescens through real-time expression analysis and confirmed its in vivo protective effect on acute pyelonephritis infection in rat model with satisfactory safety evaluated by single dose toxicity studies.

Biofilms are the aggregation of microorganism, wherein the microbial cells stick to each other on biotic and abiotic surfaces and composed of extracellular DNA, polysaccharides and proteins (Abdel-Aziz and Aeron, 2014). Therefore, we tested the effect of phytol on biofilm formation and EPS production in $S$. marcescens by XTT reduction and EPS quantification assays. The

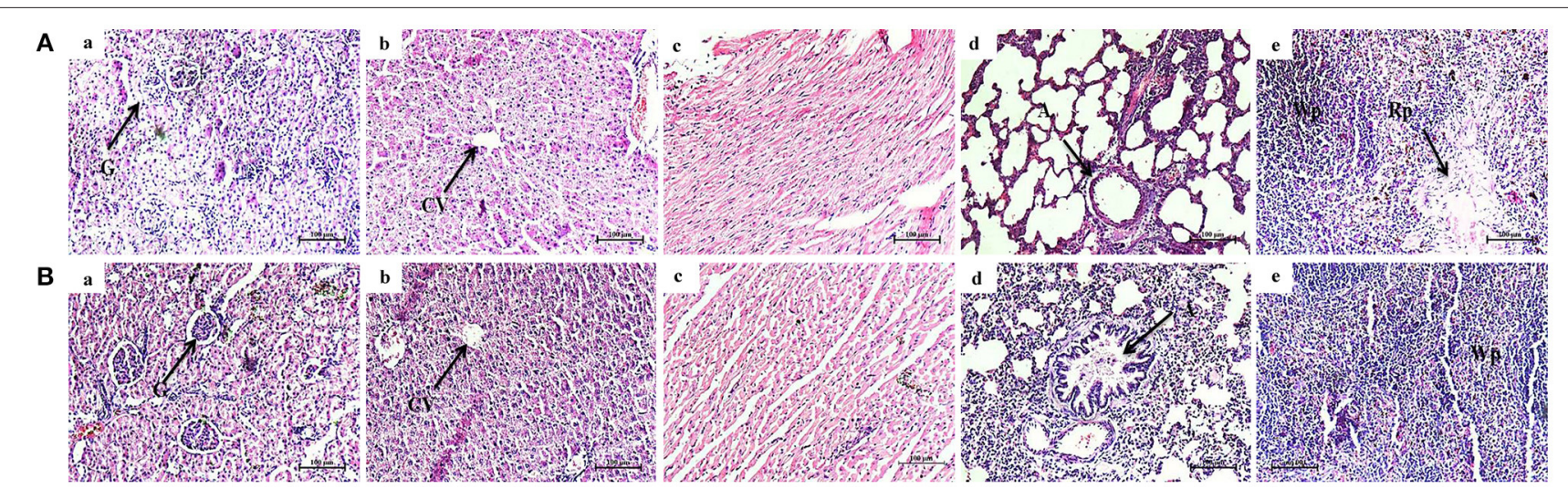

FIGURE 10 | Histopathology analysis of vital organs. Phytol treatment (200 mg/kg) (B) did not show any considerable histology varitions in vital organs such as kidney (a), liver (b), heart (c), lungs (d), and spleen (e), compared to the vital organs of animal control (A). G, Glomeruli; CV, Central Vein; A, Alveolar; Wp, White pulp; Rp, Red pulp. 
obtained results showed decreasing level of metabolically active cells involved in biofilm formation and EPS production in phytol treatment compared to their respective controls (Figures 2A, 4A). Further, the light and $\operatorname{CLSM}(2,2.5$, and 3 D) images confirmed the antibiofilm potential of phytol, in which, the 5 and $10 \mu \mathrm{g} / \mathrm{ml}$ of phytol treatment showed disintegration of biofilm formation. Divergently, the control slides showed thick coating of biofilm formation (Figures 3A,B). Our results are going well with the findings of the previous researches, who have reported that the morin reduced the metabolically active cells involved in Listeria monocytogenes biofilm formation (Sivaranjani et al., 2016) and marine bacterial extract G-16 effectively inhibited the S. marcescens EPS production (Padmavathi et al., 2014).

Several bacterial pathogens simultaneously grow and spread rapidly over a surface through the pattern of movement called swarming motility. This diminishes competition between bacterial cells for nutrients and speeding their growth (Kaiser, 2007). This typical virulent phenomenon in S. marcescens plays a vital role in catheter associated urinary tract infections. In this bacterial species the phenomenon of swimming and swarming motility is associated with QS. Hence, an attempt was made to examine the QSI potential of phytol in inhibiting the swarming movement. Results of the current study showed vigorous swarming motility in the untreated $S$. marcescens control plate, wherein the 5 and $10 \mu \mathrm{g} / \mathrm{ml}$ of phytol treatment showed concentration dependent swarming motility inhibition (Figure 3C). Consistent with this result, Srinivasan et al. (2016) have reported that Piper betle extract effectively inhibited the $S$. marcescens swarming motility in a concentration dependent manner.

Lipase is the secreted extracellular virulence enzyme in $S$. marcescens and their production is regulated by QS. Hemolysin production is accountable for the pathogenesis of various bacterial pathogens. Hemolysin produced by $S$. marcescens (ShlA), is a group of pore forming toxins, targets the cell membrane permeability (Shimuta et al., 2009). The result of lipase and hemolysin inhibition assays indicated a significant $(P \leq 0.0005)$ decline in lipase and hemolysin production in $S$. marcescens upon treatment with 5 and $10 \mu \mathrm{g} / \mathrm{ml}$ of phytol (Figures 4A,B). Previously, Anethum graveolens extract and farnesol were tested for their effects on lipase and hemolysin production in $S$. marcescens and $P$. aeruginosa respectively, and which showed promising lipase and hemolysin inhibitory properties (Hassan Abdel-Rhman et al., 2015; Salini and Pandian, 2015).

Further to understand the anti-QS and antibiofilm potential of phytol at molecular level and to support the outcome of in vitro results, the real-time PCR analysis was performed. It is known that fimA and fim $C$ are the major fimbrial subunits in S. marcescens. In 2007 , a study done by Labbate et al. disclosed that the fimA disruption mutant unable to produce fimbriae and likewise they confirmed the absence of fimbrial structure in $S$. marcescens by electron microscopy. The products of the flhDC master operon, FlhD and FlhC are global gene regulators in $S$. marcescens, which expressed several inherent determinants such as cell differentiation, cell division, swimming and swarming motilities (Liu et al., 2000). Therefore, the impact of phytol on the fimA, fim $C$, flhC, and $f$ h D gene expression levels were tested and the obtained real-time data showed a substantial downregulation of these fimbrial and motility genes expression in $S$. marcescens. The $b s m B$ is a QS controlled virulence gene in $S$. marcescens. Labbate et al. (2007) reported that the bsmB mutant lacked biofilm formation, lipase, protease and S-layer protein productions. Phytol treatment decreases the expression level of bsmB gene up to 0.36 -fold compare to the control. The RssARssB (RssA-sensor kinase and RssB -response regulator) is a two component system and it negatively regulates the $S$. marcescens swarming motility. RssB binds directly to the $f h D C$ promoter and suppresses the $f h D C$ transcription, leading to reduced production of hemolysin and flagellar mediated motilities (Lin et al., 2010). In Ang et al. (2001) stated that the overexpression of rsmA gene in $S$. marcescens inhibits the swarming motility and prodigiosin production. The pigP is the master transcriptional regulator and which controls the regulation of prodigiosin pigment production in $S$. marcescens under the QS mechanism (Gristwood et al., 2011). RssB binds directly to the promoter region of the pig operon, leading to negative regulation of prodigiosin production (Soo et al., 2014). The outcome of realtime data showed upregulation of $r s s B$ and $r s m A$ genes expression and support the in vitro data of hemolysin, swarming motility and prodigiosin inhibition due to their binding on flhDC and pigP promoter regions. Likewise, phytol decreases the expression level of pigP gene upto 0.48 fold compare to the control. ShlA is a key virulence factor of $S$. marcescens, which has shown to wield cytotoxic effects on fibroblasts and epithelial cells (Di Venanzio et al., 2014) and shlBA mutant strains were extremely reduced in virulence in mice, Drosophila melanogaster and Caenorhabditis elegans models (Kurz et al., 2003). In S. marcescens, hemolysis and swarming motility are co-regulated (Shanks et al., 2013). In the current study the phytol inhibited the hemolysin production along with swarming motility inhibition. Similarly, the real-time data showed downregulation of $s h l A$ gene upon treatment with phytol (Figure 5).

The recent reports stated that the QS mediated virulence factors are very important for establishment of successful UTI infection in animal models (Kumar et al., 2009; Gupta et al., 2013b, 2016; Saini et al., 2015). Only limited studies specified the pathogenesis of $S$. marcescens in animal models and also no reports are available on the protective effect of plant extracts or pure compounds against $S$. marcescens associated infection in animal models. To the best of our knowledge, the present study is the first of its kind has been made with a prime objective to establish the $S$. marcescens associated acute pyelonephritis in rat and assessing the protective effect of phytol against acute pyelonephritis induced rat.

After successful establishment of acute pyelonephritis in rat model, the bacterial count in phytol treated and untreated rats were quantified by bacteriological assay. The infected control had $8.28 \times 10^{4}, 7.2 \times 10^{4}$, and $3.72 \times 10^{4} \mathrm{CFU}$ in kidney, bladder and urine samples, respectively compare to the $200 \mathrm{mg} / \mathrm{kg}$ body weight of phytol treated group in which $1.78 \times 10^{4}, 0.96 \times$ $10^{4}$, and $0.5 \times 10^{4} \mathrm{CFU}$ were observed in kidney, bladder and urine samples, respectively (Figures 6B-D). This corresponds to nearly $4.6,7.5$ and 7.4 fold decrease in bacterial count in 
phytol (200 mg/kg body weight) treated kidney, bladder and urine samples respectively, compared to the infected control. These results correlate with the findings of Hvidberg et al. (2000), who have reported that the antibiotic gentamicin treatment significantly decreased the bacterial count in kidney, bladder and urine samples in UTI induced mice compare to the infection control.

Colonization of bacterial pathogens on host tissue during the early stage of infection is an essential factor for the establishment of very infection. Virulence factors produced by the bacterial pathogens help in the host colonization and subsequent infection progress. The extracellular virulence enzyme protease plays a pivotal role in the pathogenesis of $S$. marcescens during infection and induces interleukin- 6 and interleukin- 8 mRNA expression through protease-activated receptor 2 (PAR-2) (Kida et al., 2007). A study made by Lyerly and Kreger (1983) state that the highly purified protease enzyme obtained from S. marcescens induced the acute pneumonia in mice and guinea pigs. A finding made by Ishii et al. (2014) revealed that the protease intricate in the pathogenesis of $S$. marcescens and leads to a huge loss of hemolymph in silkworm larvae. Like protease, the extracellular lipase enzyme also an extensive virulence factor and which involved in the pathogenesis of $S$. marcescens (Hejazi and Falkiner, 1997). Both of these virulence enzyme productions are controlled by the QS mechanism (Labbate et al., 2007). In support, the result stated by Elsheikh et al. (1987) indicated that the virulence enzyme protease enhances the pathogenesis of $P$. aeruginosa in experimental mouse burn infection. In Gupta et al. (2013a) suggested that the QS mediated virulence enzymes such as protease and elastase are involved in the establishment and colonization of $P$. aeruginosa in mice during experimental UTI. Therefore, the inhibitory effect of phytol on virulence enzyme production in rat acute pyelonephritis model was evaluated. As expected the phytol treatment showed decreased level of protease and lipase enzymes production in both kidney and bladder tissues compared to the infected and vehicle controls (Figure 7). The extreme reduction in virulence enzyme productions of kidney and bladder tissues in phytol treated groups is go well with bacteriological assay. Hence, it is envisaged that the decreasing level of virulence enzymes in phytol treated groups might be due to the decreasing level of invading $S$. marcescens cells.

MDA is an indicator of lipid peroxidation and which is a steady product of oxidative stress of reactive oxygen species on unsaturated fatty acid, a vital constituent of cell membrane. In the current study, the kidney and bladder tissues from infected and vehicle control groups showed a substantial increase in MDA level on 5th p.i.d, whereas the phytol treated groups showed decreasing level of MDA production in kidney and bladder tissues (Figure 8A). Consistent with our results, synergistic combination of azithromycin and ciprofloxacin has been shown to decrease the MDA level in kidney tissue homogenates of $P$. aeruginosa infected mice on the 3rd and 5th p.i.d (Saini et al., 2015).

MPO is an enzyme deposited in azurophilic granules of polymorphonuclear neutrophils and macrophages, which released during inflammatory process and oxidative stress into extracellular fluid. The MPO is a possible pathological marker for the confirmation of inflammation (Loria et al., 2008). In the present study, the MPO level was considerably low in case of infected rats treated with phytol compare to the infected and vehicle controls in both kidney and bladder tissues (Figure 8B). The results of MPO assay go well with the findings of Vadekeetil et al. (2016), who have reported that the ajoene-ciprofloxacin combination effectively decreasing the MPO production in the mice infected from $P$. aeruginosa biofilm associated murine acute pyelonephritis.

NO is produced by a different cell types by NO synthases, which are involved in the inflammatory processes. Stimulation of NO production during inflammatory progression signifies a protection mechanism against invading bacterial pathogens, however extreme formation of NO has also been involved in host tissue injury (Van Der Vliet et al., 1997). A significant $(P \leq$ 0.0005 ) decline of nitrite in the levels of protein was observed in kidney and bladder tissues of phytol treatment groups compare to the infection and vehicle controls. Similar to the observed results, recently the combination therapy with ajoene and ciprofloxacin has been found to show decreasing level of NO production in mice infected with $P$. aeruginosa (Vadekeetil et al., 2016).

To support the decreasing level of virulence enzymes and inflammatory markers in phytol treated groups, the histopathology analysis was done. Kidney sections of the normal uninfected rats looked histologically normal with no substantial pathological variations (Figure 9Aa). The kidney sections of infection and vehicle control rats had extensive infiltration of neutrophils with destruction of renal tubules and shrinkage of glomeruli (Figures 9Ab,c). In case of $100 \mathrm{mg} / \mathrm{kg}$ body weight of phytol treated group, a mild infiltration of neutrophils was noted and $200 \mathrm{mg} / \mathrm{kg}$ body weight of phytol treatment showed no considerable pathological changes (Figures 9Ad,e). Recently, Balamurugan et al. (2015) found that the treatment of UTI ${ }^{\mathrm{QQ}}$ with gentamicin against rats infected with $S$. aureus showed minimal dilatation of renal tubules with no considerable pathological changes in kidney section. The bladder histology section of infection and vehicle controls showed extensive infiltration of neutrophils with severe abrasion in transitional epithelium (Figures 9Bb,c). In contrast, the uninfected rat and infected rat treated with phytol showed no considerable pathological changes (Figures $\mathbf{9 B a}, \mathbf{d}, \mathbf{e}$ ). Outcome of this bladder histology supports the results of Sabharwal et al. (2016), who have not observed any adverse pathological changes in divalent flagellin treated mice bladder tissue.

The toxicological property of phytol has been tested in different animal models for different clinical applications (Hidiroglou and Jenkins, 1972; McGinty et al., 2010). The acute oral $\mathrm{LD}_{50}$ of phytol in rats was described to be more than $5.0 \mathrm{~g} / \mathrm{kg}$ body weight (McGinty et al., 2010). However, the rats were dosed for 28-day in sub chronic toxicity study showed the no-observedadverse-effect-level (NOAEL) of phytol to be $500 \mathrm{mg} / \mathrm{kg} /$ day, based on organ weight changes. In contrast, the rats were dosed for a longer period of time (52-108 days) in a one-generation reproductive toxicity study, the lowest-observed-adverse-effect level (LOAEL) of phytol was to be $250 \mathrm{mg} / \mathrm{kg} /$ day, based on renal changes in male and female rats (Api et al., 2016). The overall mammalian toxicity of phytol is considered to be low only in least 
concentration. Hence, the protective effect of phytol was tested against $S$. marcescens associated acute pyelonephritis infection at the concentration of 100 and $200 \mathrm{mg} / \mathrm{kg}$. On the other hand, we assessed the toxic effect of phytol $(200 \mathrm{mg} / \mathrm{kg})$ by single dose acute toxicity study. No significant differences were observed in the hematological profile of phytol treated group compared to the animal control (Table 3). The oral administration of phytol in rats did not show any significant changes in biochemical profile when compared to the animal control group (Table 3). However, an increase in ALP and SGPT serum blood levels were observed in the phytol treatment. ALP and SGPT are generally used as markers for liver function and indicators of liver toxicity. ALP and SGPT levels elevate in the blood when the hepatic cellular permeability is changed or cellular injury occurs in liver. The histopathological analysis of vital organs (Kidney, Liver, Heart, Lungs, and Spleen) in phytol treated group did not show any adverse pathological effects compared to the animal control, except liver section (Figure 10). The liver section of phytol treatment showed moderate degeneration of hepatocytes (Figure 10Bb) and it was due to the increasing level of ALP and SGPT. The degeneration of hepatocytes and increasing level of liver enzymes support the outcome of Mackie et al. (2009), who have reported that the phytol induced the hepatotoxicity in mice.

To the best of our knowledge, this is the pioneering study annex the anti-QS and antibiofilm capability of phytol in the counteractive action on $S$. marcescens infection through the serious of virulence inhibition assays. The real-time analysis disclosed the molecular mechanism of phytol on QS intervened virulence factors productions in $S$. marcescens. Further, the S. marcescens associated acute pyelonephritis infection in rat model unveiled the protective effect of phytol by reducing the bacterial counts, virulence enzymes and inflammatory markers productions with adequate safety. Therefore, the utilization of phytol is promising in the advancement of novel antipathogenic medications to control acute pyelonephritis infection caused by S. marcescens. However, further studies will be needed to reveal

\section{REFERENCES}

Abdel-Aziz, S. M., and Aeron, A. (2014). Bacterial biofilm: dispersal and inhibition strategies. SaJ Biotechnol. 1:105. doi: 10.18875/2375-6713.1.105

Ang, S., Horng, Y. T., Shu, J. C., Soo, P. C., Liu, J. H., Yi, W. C., et al. (2001). The role of RsmA in the regulation of swarming motility in Serratia marcescens. J. Biomed. Sci. 8, 160-169. doi: 10.1159/000054028

Api, A. M., Belsito, D., Bhatia, S., Bruze, M., Calow, P., Dagli, M. L., et al. (2016). RIFM fragrance ingredient safety assessment, $\alpha$-Ionone, CAS Registry Number 127-41-3. Food Chem. Toxicol. 97, S1-S10. doi: 10.1016/j.fct.2015.12.010

Balamurugan, P., Hema, M., Kaur, G., Sridharan, V., Prabu, P. C., Sumana, M. N., et al. (2015). Development of a biofilm inhibitor molecule against multidrug resistant Staphylococcus aureus associated with gestational urinary tract infections. Front Microbiol. 6:832. doi: 10.3389/fmicb.2015.00832

Behzadi, P., Behzadi, E., Yazdanbod, H., Aghapour, R., Cheshmeh, M. A., and Omran, D. S. (2010). A survey on urinary tract infections associated with the three most common uropathogenic bacteria. Maedica 5:111.

Brown, C. (2011). Urethral catheterization of the female rat. Lab. Anim. 40:111. doi: 10.1038/laban0411-111

Chen, C. Y., Chen, Y. H., Lu, P. L., Lin, W. R., Chen, T. C., and Lin, C. Y. (2012). Proteus mirabilis urinary tract infection and bacteremia: risk factors, the mode of action of phytol against $S$. marcescens associated acute pyelonephritis infection.

\section{AUTHOR CONTRIBUTIONS}

$\mathrm{AV}$ and RS conceived and designed the research; RS, AK, and VK performed the experiments; RM, KR, and GA offered advice and technical assistance for carrying out the studies on experimental animals; AV and RS analyzed the data; AV, SK, and KR contributed reagents/materials/analysis tools; RS wrote the paper and AV approved the manuscript after careful analysis.

\section{ACKNOWLEDGMENTS}

The authors RS, AK, SK, and AV thankfully acknowledge the Bioinformatics Infrastructure Facility provided by the Alagappa University [Funded by Department of Biotechnology, Government of India; Grant No. BT/BI/25/015/2012(BIF)]. The author RS sincerely thanks the University Grants Commission, New Delhi, India, for the financial support in the form of UGCBSR fellowship [F.4-1/2006(BSR)/7-326/2011(BSR)]. The author GA thankfully acknowledges UGC for the award UGC-BSR faculty fellow. The author KR thank the DST supported "National Facility on Drug development for Academia, Pharmaceutical and Allied Industries" established at BIT Campus, Anna University, Tiruchirappalli. The authors thankfully acknowledge Dr. Claus Sternberg, DTU Systems Biology, Technical University of Denmark for providing the COMSTAT software.

\section{SUPPLEMENTARY MATERIAL}

The Supplementary Material for this article can be found online at: https://www.frontiersin.org/articles/10.3389/fcimb. 2017.00498/full\#supplementary-material

Supplementary Figure 1 | PCR amplification for the checking the primer efficiencies of QS controlled virulence genes in S. marcescens. clinical presentation, and outcomes. J. Microbiol. Immunol. Infect. 45, 228-236. doi: 10.1016/j.jmii.2011.11.007

Derbie, A., Hailu, D., Mekonnen, D., Abera, B., and Yitayew, G. (2017). Antibiogram profile of uropathogens isolated at Bahir Dar Regional Health Research Laboratory Centre, Northwest Ethiopia. Pan. Afr. Med. J. 26:134. doi: 10.11604/pamj.2017.26.134.7827

Di Venanzio, G., Stepanenko, T. M., and Véscovi, E. G. (2014). Serratia marcescens ShlA pore-forming toxin is responsible for early induction of autophagy in host cells and is transcriptionally regulated by RcsB. Infect. Immun. 82, 3542-3554. doi: 10.1128/IAI.01682-14

Eberl, L., Winson, M. K., Sternberg, C., Stewart, G. S., Christiansen, G., Chhabra, S. R., et al. (1996). Involvement of N-acyl-1-homoserine lactone autoinducers in controlling the multicellular behaviour of Serratia liquefaciens. Mol. Microbiol. 20, 127-136. doi: 10.1111/j.1365-2958.1996.tb02495.x

Elsheikh, L. E., Kronevi, T., Wretlind, B., Abaas, S., and Iglewski, B. H. (1987). Assessment of elastase as a Pseudomonas aeruginosa virulence factor in experimental lung infection in mink. Vet Microbiol. 13, 281-289. doi: 10.1016/0378-1135(87)90090-3

Foxman, B., and Brown, P. (2003). Epidemiology of urinary tract infections: transmission and risk factors, incidence, and costs. Infect. Dis. Clin. North Am. 17, 227-241. doi: 10.1016/S0891-5520(03)00005-9 
González-Juarbe, N., Mares, C. A., Hinojosa, C. A., Medina, J. L., Cantwell, A., Dube, P. H., et al. (2015). Requirement for Serratia marcescens cytolysin in a murine model of hemorrhagic pneumonia. Infect. Immun. 83, 614-624. doi: 10.1128/IAI.01822-14

Gristwood, T., McNeil, M. B., Clulow, J. S., Salmond, G. P., and Fineran, P. C. (2011). PigS and PigP regulate prodigiosin biosynthesis in Serratia via differential control of divergent operons, which include predicted transporters of sulfur-containing molecules. J. Bacteriol. 193, 1076-1085. doi: 10.1128/JB.00352-10

Gupta, P., Gupta, R. K., and Harjai, K. (2013a). Multiple virulence factors regulated by quorum sensing may help in establishment and colonisation of urinary tract by Pseudomonas aeruginosa during experimental urinary tract infection. Ind. J. Med. Microbiol. 31:29. doi: 10.4103/0255-0857.108715

Gupta, P., Gupta, R. K., and Harjai, K. (2013b). Quorum sensing signal molecules produced by Pseudomonas aeruginosa cause inflammation and escape host factors in murine model of urinary tract infection. Inflammation 36, 1153-1159. doi: 10.1007/s10753-013-9650-y

Gupta, R. K., Harjai, K., and Chhibber, S. (2016). Rhl quorum sensing affects the virulence potential of Pseudomonas aeruginosa in an experimental urinary tract infection. Antonie Leeuwenhoek 109, 1535-1544. doi: 10.1007/s10482-016-0755-9

Hassan Abdel-Rhman, S., Mostafa El-Mahdy, A., and El-Mowafy, M. (2015). Effect of tyrosol and farnesol on virulence and antibiotic resistance of clinical isolates of Pseudomonas aeruginosa. BioMed. Res. Int. 2015:456463. doi: $10.1155 / 2015 / 456463$

Hejazi, A., and Falkiner, F. R. (1997). Serratia marcescens. J. Med. Microbiol. 46, 903-912. doi: 10.1099/00222615-46-11-903

Heydorn, A., Nielsen, A. T., Hentzer, M., Sternberg, C., Givskov, M., Ersbøll, B. K., et al. (2000). Quantification of biofilm structures by the novel computer program COMSTAT. Microbiology 146, 2395-2407. doi: 10.1099/00221287-146-10-2395

Hidiroglou, M., and Jenkins, K. J. (1972). Fate of 14 C-phytoI Administered Orally to Sheep. Can. J. Physiol. Pharmacol. 50, 458-462. doi: 10.1139/y72-069

Hines, D. A., Saurugger, P. N., Ihler, G. M., and Benedik, M. J. (1988). Genetic analysis of extracellular proteins of Serratia marcescens. J. Bacteriol. 170, 4141-4146. doi: 10.1128/jb.170.9.4141-4146.1988

Hirs, C. H. W. (1967). [45] Glycopeptides. Methods Enzymol. 11, 411-413. doi: 10.1016/S0076-6879(67)11047-1

Horng, Y. T., Deng, S. C., Daykin, M., Soo, P. C., Wei, J. R., Luh, K. T., et al. (2002). The LuxR family protein SpnR functions as a negative regulator of $\mathrm{N}$-acylhomoserine lactone-dependent quorum sensing in Serratia marcescens. Mol. Microbiol. 45, 1655-1671. doi: 10.1046/j.1365-2958.2002.03117.x

Hvidberg, H., Struve, C., Krogfelt, K. A., Christensen, N., Rasmussen, S. N., and Frimodt-Møller, N. (2000). Development of a long-term ascending urinary tract infection mouse model for antibiotic treatment studies. Antimicrob. Agents Chemother. 44, 156-163. doi: 10.1128/AAC.44.1.156-163.2000

Inoue, Y., Hada, T., Shiraishi, A., Hirose, K., Hamashima, H., and Kobayashi, S. (2005). Biphasic effects of geranylgeraniol, teprenone, and phytol on the growth of Staphylococcus aureus. Antimicrob. Agents Chemother. 49, 1770-1774. doi: 10.1128/AAC.49.5.1770-1774.2005

Ishii, K., Adachi, T., Hara, T., Hamamoto, H., and Sekimizu, K. (2014). Identification of a Serratia marcescens virulence factor that promotes hemolymph bleeding in the silkworm, Bombyx mori. J Invertebr Pathol. 117, 61-67. doi: 10.1016/j.jip.2014.02.001

Islam, M. T., de Alencar, M. V. O. B., da Conceição Machado, K., da Conceição Machado, K., de Carvalho Melo-Cavalcante, A. A., de Sousa, D. P., et al. (2015). Phytol in a pharma-medico-stance. Chem. Biol. Interact. 240, 60-73. doi: 10.1016/j.cbi.2015.07.010

Kaiser, D. (2007). Bacterial swarming: a re-examination of cell-movement patterns. Curr. Biol. 17, R561-R570. doi: 10.1016/j.cub.2007.04.050

Kannappan, A., Gowrishankar, S., Srinivasan, R., Pandian, S. K., and Ravi, A. V. (2017). Antibiofilm activity of Vetiveria zizanioides root extract against methicillin-resistant Staphylococcus aureus. Microb. Pathog. 110, 313-324. doi: 10.1016/j.micpath.2017.07.016

Katsiari, M., Nikolaou, C., Roussou, Z., Triantopoulou, C., Apessou, D., Platsouka, E. D., et al. (2012). Community acquired quinolone-resistant Escherichia coli pyelonephritis complicated with multiple renal abscesses: a case report. Hippokratia. 16:381.
Kaur, N., Sharma, S., Malhotra, S., Madan, P., and Hans, C. (2014). Urinary tract infection: aetiology and antimicrobial resistance pattern in infants from A Tertiary Care Hospital in North India. J. Clin. Diagn. Res. 8, DC01-DC03. doi: 10.7860/JCDR/2014/8772.4919

Kida, Y., Inoue, H., Shimizu, T., and Kuwano, K. (2007). Serratia marcescens serralysin induces inflammatory responses through protease-activated receptor 2. Infect. Immun. 75, 164-174. doi: 10.1128/IAI.01239-06

Kim, J. J., Shajib, M. S., Manocha, M. M., and Khan, W. I. (2012). Investigating intestinal inflammation in DSS-induced model of IBD. J. Vis. Exp. e3678. doi: $10.3791 / 3678$

Kim, S. Y., Shin, J., Shin, S. Y., and Ko, K. S. (2013). Characteristics of carbapenemresistant Enterobacteriaceae isolates from Korea. Diagn. Microbiol. Infect. Dis. 76, 486-490. doi: 10.1016/j.diagmicrobio.2013.04.006

Kufel, W. D., Scrimenti, A., and Steele, J. M. (2016). A case of septic shock due to Serratia marcescens pyelonephritis and bacteremia in a patient receiving empagliflozin. J. Pharm. Pract. 30, 672-675. doi: 10.1177/0897190016679760

Kumar, R., Chhibber, S., and Harjai, K. (2009). Quorum sensing is necessary for the virulence of Pseudomonas aeruginosa during urinary tract infection. Kidney Int. 76, 286-292. doi: 10.1038/ki.2009.183

Kurz, C. L., Chauvet, S., Andrès, E., Aurouze, M., Vallet, I., Michel, G. P. F., et al. (2003). Virulence factors of the human opportunistic pathogen Serratia marcescens identified by in vivo screening. EMBO J. 22, 1451-1460. doi: 10.1093/emboj/cdg159

Labbate, M., Zhu, H., Thung, L., Bandara, R., Larsen, M. R., Willcox, M. D., et al. (2007). Quorum-sensing regulation of adhesion in Serratia marcescens MG1 is surface dependent. J. Bacteriol. 189, 2702-2711. doi: 10.1128/JB. 01582-06

Leclercq, R., Cantón, R., Brown, D. F., Giske, C. G., Heisig, P., MacGowan, A. P., et al. (2013). EUCAST expert rules in antimicrobial susceptibility testing. Clin. Microbiol. Infect. 19, 141-160. doi: 10.1111/j.1469-0691.2011.03703.x

Lee, H. K., Park, Y. J., Kim, J. Y., Chang, E., Cho, S. G., Chae, H. S., et al. (2005). Prevalence of decreased susceptibility to carbapenems among Serratia marcescens, Enterobacter cloacae, and Citrobacter freundii and investigation of carbapenemases. Diagn. Microbiol. Infect. Dis. 52, 331-336. doi: 10.1016/j.diagmicrobio.2005.04.012

Lee, W., Woo, E. R., and Lee, D. G. (2016). Phytol has antibacterial property by inducing oxidative stress response in Pseudomonas aeruginosa. Free Radic Res. 50, 1309-1318. doi: 10.1080/10715762.2016.1241395

Lim, S. Y., Meyer, M., Kjonaas, R. A., and Ghosh, S. K. (2006). Phytol-based novel adjuvants in vaccine formulation: 1 . assessment of safety and efficacy during stimulation of humoral and cell-mediated immune responses. J. Immune Based Ther. Vaccines 4:6. doi: 10.1186/1476-8518-4-6

Lin, C. S., Horng, J. T., Yang, C. H., Tsai, Y. H., Su, L. H., Wei, C. F., et al. (2010). RssAB-FlhDC-ShlBA as a major pathogenesis pathway in Serratia marcescens. Infect Immun. 78, 4870-4881. doi: 10.1128/IAI.00661-10

Liou, B. H., Duh, R. W., Lin, Y. T., Lauderdale, T. L. Y., and Fung, C. P. (2014). A multicenter surveillance of antimicrobial resistance in Serratia marcescens in Taiwan. J. Microbiol. Immunol. Infect. 47, 387-393. doi: $10.1016 /$ j.jmii.2013.04.003

Liu, J. H., Lai, M. J., Ang, S., Shu, J. C., Soo, P. C., Horng, Y. T., et al. (2000). Role of flhDC in the expression of the nuclease gene nucA, cell division and flagellar synthesis in Serratia marcescens. J. Biomed. Sci. 7, 475-483. doi: $10.1159 / 000025483$

Loria, V., Dato, I., Graziani, F., and Biasucci, L. M. (2008). Myeloperoxidase: a new biomarker of inflammation in ischemic heart disease and acute coronary syndromes. Mediat. Inflamm. 2008:135625. doi: 10.1155/2008/135625

Lyerly, D. M., and Kreger, A. S. (1983). Importance of serratia protease in the pathogenesis of experimental Serratia marcescens pneumonia. Infect Immun. $40,113-119$.

Mackie, J. T., Atshaves, B. P., Payne, H. R., McIntosh, A. L., Schroeder, F., and Kier, A. B. (2009). Phytol-induced hepatotoxicity in mice. Toxicol. Pathol. 37, 201-208. doi: 10.1177/0192623308330789

McGinty, D., Letizia, C. S., and Api, A. M. (2010). Fragrance material review on phytol. Food Chem. Toxicol. 48, S59-S63. doi: 10.1016/j.fct.2009.11.012

McMillen, M. A., Huribal, M., Cunningham, M. E., Bala, R. J., Pleban, W. E., and D'aiuto, M. L. (1996). Endothelin-1, interleukin-6, and interleukin8 levels increase in patients with burns. J. Burn. Care Res. 17, 384-389. doi: 10.1097/00004630-199609000-00003 
Mittal, R., Aggarwal, S., Sharma, S., Chhibber, S., and Harjai, K. (2009). Urinary tract infections caused by Pseudomonas aeruginosa: a minireview. J. Infect. Public Health. 2, 101-111. doi: 10.1016/j.jiph.2009.08.003

Nickel, J. C., Olson, M., McLean, R. J. C., Grant, S. K., and Costerton, J. W. (1987). An ecological study of infected urinary stone genesis in an animal model. BJU Int. 59, 21-30. doi: 10.1111/j.1464-410X.1987.tb04573.x

Nithya, C., Aravindraja, C., and Pandian, S. K. (2010). Bacillus pumilus of Palk Bay origin inhibits quorum-sensing-mediated virulence factors in Gram-negative bacteria. Res. Microbiol. 161, 293-304. doi: 10.1016/j.resmic.2010.03.002

Ohkawa, H., Ohishi, N., and Yagi, K. (1979). Assay for lipid peroxides in animal tissues by thiobarbituric acid reaction. Anal. Biochem. 95, 351-358. doi: 10.1016/0003-2697(79)90738-3

Ohno, N., Ota, Y., Hatakeyama, S., Yanagimoto, S., Morisawa, Y., Tsukada, K., et al. (2003). A patient with E. coli-induced pyelonephritis and sepsis who transiently exhibited symptoms associated with primary biliary cirrhosis. Intern. Med. 42, 1144-1148. doi: 10.2169/internalmedicine.42.1144

Packiavathy, I. A. S. V., Sasikumar, P., Pandian, S. K., and Ravi, A. V. (2013). Prevention of quorum-sensing-mediated biofilm development and virulence factors production in Vibrio spp. by curcumin. Appl. Microbiol. Biotechnol. 97, 10177-10187. doi: 10.1007/s00253-013-4704-5

Padmavathi, A. R., Abinaya, B., and Pandian, S. K. (2014). Phenol, 2, 4-bis (1, 1dimethylethyl) of marine bacterial origin inhibits quorum sensing mediated biofilm formation in the uropathogen Serratia marcescens. Biofouling 30, 1111-1122. doi: 10.1080/08927014.2014.972386

Pejin, B., Ciric, A., Glamoclija, J., Nikolic, M., and Sokovic, M. (2015). In vitro anti-quorum sensing activity of phytol. Nat. Prod. Res. 29, 374-377. doi: 10.1080/14786419.2014.945088

Pejin, B., Savic, A., Sokovic, M., Glamoclija, J., Ciric, A., Nikolic, M., et al. (2014). Further in vitro evaluation of antiradical and antimicrobial activities of phytol. Nat. Prod. Res. 28, 372-376. doi: 10.1080/14786419.2013.869692

Ramakrishnan, K., and Scheid, D. C. (2005). Diagnosis and management of acute pyelonephritis in adults. Am. Fam. Physician 71, 933-942.

Rice, S. A., Koh, K. S., Queck, S. Y., Labbate, M., Lam, K. W., and Kjelleberg, S. (2005). Biofilm formation and sloughing in Serratia marcescens are controlled by quorum sensing and nutrient cues. J. Bacteriol. 187, 3477-3485. doi: 10.1128/JB.187.10.3477-3485.2005

Rockett, K. A., Awburn, M. M., Rockett, E. J., Cowden, W. B., and Clark, I. A. (1994). Possible role of nitric oxide in malarial immunosuppression. Parasite Immunol. 16, 243-249. doi: 10.1111/j.1365-3024.1994.tb00346.x

Rumbaugh, K. P., Griswold, J. A., Iglewski, B. H., and Hamood, A. N. (1999). Contribution of quorum sensing to the virulence of pseudomonas aeruginosa in burn wound infections. Infect. Immun. 67, 5854-5862.

Rumbaugh, K. P., Hamood, A. N., and Griswold, J. A. (2004). Cytokine induction by the $P$. aeruginosa quorum sensing system during thermal injury. J. Surg. Res. 116, 137-144. doi: 10.1016/j.jss.2003.08.009

Ryu, K. R., Choi, J. Y., Chung, S., and Kim, D. H. (2011). Anti-scratching behavioral effect of the essential oil and phytol isolated from Artemisia princeps Pamp in mice. Planta Med. 77, 22-26. doi: 10.1055/s-0030-1250119

Sabharwal, N., Chhibber, S., and Harjai, K. (2016). Divalent flagellin immunotherapy provides homologous and heterologous protection in experimental urinary tract infections in mice. Int. J. Med. Microbiol. 306, 29-37. doi: 10.1016/j.ijmm.2015.11.002

Saini, H., Chhibber, S., and Harjai, K. (2015). Azithromycin and ciprofloxacin: a possible synergistic combination against Pseudomonas aeruginosa biofilmassociated urinary tract infections. Int. J. Antimicrob. Agents 45, 359-367. doi: 10.1016/j.ijantimicag.2014.11.008

Salini, R., and Pandian, S. K. (2015). Interference of quorum sensing in urinary pathogen Serratia marcescens by Anethum graveolens. Pathog. Dis. 73:ftv038. doi: $10.1093 /$ femspd/ftv038

Santos, C. C., Salvadori, M. S., Mota, V. G., Costa, L. M., de Almeida, A. A., de Oliveira, G. A., et al. (2013). Antinociceptive and antioxidant activities of phytol in vivo and in vitro models. Neurosci. J. 2013:949452. doi: 10.1155/2013/ 949452

Sathya, S., Shanmuganathan, B., Saranya, S., Vaidevi, S., Ruckmani, K., and Pandima Devi, K. (2017). Phytol-loaded PLGA nanoparticle as a modulator of Alzheimer's toxic $A \beta$ peptide aggregation and fibrillation associated with impaired neuronal cell function. Artif. Cells Nanomed. Biotechnol. 1-12. doi: 10.1080/21691401.2017.1391822

Shanks, R. M., Lahr, R. M., Stella, N. A., Arena, K. E., Brothers, K. M., Kwak, D. H., et al. (2013). A Serratia marcescens PigP homolog controls prodigiosin biosynthesis, swarming motility and hemolysis and is regulated by cAMP-CRP and HexS. PLoS ONE 8:e57634. doi: 10.1371/journal.pone.0057634

Shimuta, K., Ohnishi, M., Iyoda, S., Gotoh, N., Koizumi, N., and Watanabe, H. (2009). The hemolytic and cytolytic activities of Serratia marcescens phospholipase A (PhlA) depend on lysophospholipid production by PhlA. BMC Microbiol. 9:261. doi: 10.1186/1471-2180-9-261

Sivaranjani, M., Gowrishankar, S., Kamaladevi, A., Pandian, S. K., Balamurugan, K., and Ravi, A. V. (2016). Morin inhibits biofilm production and reduces the virulence of Listeria monocytogenes-An in vitro and in vivo approach. Int. J. Food Microbiol. 237, 73-82. doi: 10.1016/j.ijfoodmicro.2016.08.021

Soo, P. C., Horng, Y. T., Chang, Y. L., Tsai, W. W., Jeng, W. Y., Lu, C. C., et al. (2014). ManA is regulated by RssAB signaling and promotes motility in Serratia marcescens. Res. Microbiol. 165, 21-29. doi: 10.1016/j.resmic.2013.10.005

Srinivasan, R., Devi, K. R., Kannappan, A., Pandian, S. K., and Ravi, A. V. (2016). Piper betle and its bioactive metabolite phytol mitigates quorum sensing mediated virulence factors and biofilm of nosocomial pathogen Serratia marcescens in vitro. J. Ethnopharmacol. 193, 592-603. doi: 10.1016/j.jep.2016.10.017

Srinivasan, R., Durgadevi, R., Kannappan, A., and Ravi, A. V. (2017b). Inhibition of quorum sensing-dependent biofilm and virulence genes expression in environmental pathogen Serratia marcescens by petroselinic acid. Antonie van Leeuwenhoek. doi: 10.1007/s10482-017-0971-y. [Epub ahead of print].

Srinivasan, R., Santhakumari, S., and Ravi, A. V. (2017a). In vitro antibiofilm efficacy of Piper betle against quorum sensing mediated biofilm formation of luminescent Vibrio harveyi. Microb. Pathog. 110, 232-239. doi: 10.1016/j.micpath.2017.07.001

Su, L. H., Ou, J. T., Leu, H. S., Chiang, P. C., Chiu, Y. P., Chia, J. H., et al. (2003). Extended epidemic of nosocomial urinary tract infections caused by Serratia marcescens. J. Clin. Microbiol. 41, 4726-4732. doi: 10.1128/JCM.41.10.4726-4732.2003

Vadekeetil, A., Saini, H., Chhibber, S., and Harjai, K. (2016). Exploiting the antivirulence efficacy of an ajoene-ciprofloxacin combination against Pseudomonas aeruginosa biofilm associated murine acute pyelonephritis. Biofouling 32, 371-382. doi: 10.1080/08927014.2015.1137289

Van Der Vliet, A., Eiserich, J. P., Halliwell, B., and Cross, C. E. (1997). Formation of reactive nitrogen species during peroxidase-catalyzed oxidation of nitrite a potential additional mechanism of nitric oxide-dependent toxicity. J. Biol. Chem. 272, 7617-7625. doi: 10.1074/jbc.272.12.7617

Youn, Y. K., LaLonde, C., and Demling, R. (1992). The role of mediators in the response to thermal injury. World J. Surg. 16, 30-36. doi: 10.1007/BF02067111

Conflict of Interest Statement: The authors declare that the research was conducted in the absence of any commercial or financial relationships that could be construed as a potential conflict of interest.

Copyright (C) 2017 Srinivasan, Mohankumar, Kannappan, Karthick Raja, Archunan, Karutha Pandian, Ruckmani and Veera Ravi. This is an open-access article distributed under the terms of the Creative Commons Attribution License (CC BY). The use, distribution or reproduction in other forums is permitted, provided the original author(s) or licensor are credited and that the original publication in this journal is cited, in accordance with accepted academic practice. No use, distribution or reproduction is permitted which does not comply with these terms. 